\title{
Avoiding the Curves: Direct Elicitation of Time Preferences
}

\author{
Susan K. Laury*1, Melayne Morgan McInnes ${ }^{\dagger 2}$, J. Todd Swarthout ${ }^{\ddagger 1}$, and Erica Von \\ Nessen $^{\S 2}$ \\ ${ }^{1}$ Department of Economics, Georgia State University \\ ${ }^{2}$ Department of Economics, University of South Carolina
}

March 22, 2012

\begin{abstract}
We propose and test a new method for eliciting curvature-controlled discount rates that are invariant to the form of the utility function. Our method uses a single elicitation task and has the advantage of obtaining individual discount rates without knowledge of risk attitude or parametric assumptions about the form of the utility function. We compare our method to the Andersen et al. (2008) double elicitation technique in which the utility function and discount rate are jointly estimated. We use a laboratory experiment to perform a within-subjects comparison of discount rates from these two methods and find consistent results, which is reassuring given the wide range of estimates in the literature. In addition, the estimated discount rates in our study are "plausibly low" in contrast to the vast majority of discount rate studies. Our results are robust to relaxing the expected utility assumption of linearity in the probabilities, as we find little evidence of probability weighting in our data. In a second experiment, we find that discount rates are not sensitive to the length of the horizon, but are sensitive to the length of the front-end delay, suggesting present bias. We estimate average discount rates to be 12.2 percent in the first experiment and 11.3 percent in the second experiment when the front-end delay is at least two weeks.
\end{abstract}

\section{Introduction}

A better understanding of how people weigh future consumption against current consumption is crucial to understanding many economic decisions. These decisions are important at both the individual level (e.g., how much one should invest in education, health care and savings) and the societal level (e.g., how much to invest in environmental preservation or damage amelioration). That said, there is no clear consensus regarding the amount by which future consumption is discounted. Reported discount rates have ranged from negative six percent to essentially infinity in various studies. ${ }^{1}$ The disparity in observed discount rates is not entirely surprising given the methodological differences across studies. Differences include the source of data (field, survey, or laboratory), the type of good studied (including goods as diverse as appliances, money, pain in the form of electric shock, or heroin), and whether the observed choices have real consequences.

\footnotetext{
*slaury@gsu.edu

$\dagger^{\dagger}$ mcinnes@moore.sc.edu

† swarthout@gsu.edu

$\S$ erica.vonnessen@gmail.com

${ }^{1}$ See Frederick et al. (2002) for a review of the literature.
} 
A recent focus of discount rate research addresses an important confound in most of the earlier literature. Previous estimates, such as those from the widely-cited Coller and Williams (1999) study, assume preferences are linear in wealth. Linear preferences are consistent with a risk-neutral decision maker; however, many studies provide direct evidence of widespread risk aversion, even over small monetary outcomes (e.g., Binswanger, 1980; Hey and Orme, 1994). If preferences are in fact concave rather than linear, the result of estimation incorrectly assuming linearity will be a positive bias in estimated discount rates (Andersen et al., 2008). Given that individual risk aversion increases with the size of the stakes (Holt and Laury, 2002), the bias becomes more severe in discount rate experiments that use higher stakes. Thus a more appropriate specification of discount-rate models should include a curvature-correction for such non-linearity in the utility function.

Recent work has suggested approaches to account for the influence of risk aversion on time preferences. Andersen et al. (2008) measure both risk and time preferences for each subject by using the procedure of Coller and Williams (1999) to elicit discount rates and the procedure of Holt and Laury (2002) to elicit risk attitudes. By jointly estimating both risk and time preferences, they obtain an estimated aggregate discount rate of 10.1 percent per year, which is significantly lower than under the assumption of linear utility. However, other recent studies that account for the curvature of the utility function in different ways (and also offer real, monetary rewards) have found vastly different results. Takeuchi (2011) uses an alternative procedure to estimate discount rates that is theoretically invariant to utility curvature, and estimates an average annual discount rate of 726 percent. Andreoni and Sprenger (2012) avoid the bias of linear preferences by eliciting time preferences with convex budget sets, and estimate an aggregate discount rate of 30 percent per year. Coble and Lusk (2010) use a joint estimation approach to estimate a Kreps-Porteus model (Kreps and Porteus, 1978) that nests the discounted expected utility model as a special case. Given their assumption of constant elasticity of substitution, they reject the discounted expected utility model and estimate a relatively high discount rate of 51.3 percent. Rohde (2010) presents a theoretical framework for eliciting preferences over outcomes with fixed payoffs but variable delays and using responses to develop the "hyperbolic factor," a measure of the time inconsistency of preferences that does not require specifying or estimating a utility function.

In this paper, we propose and test a new method for eliciting discount rates that yields curvaturecontrolled discount rates that are invariant to the form of the utility function. Following the suggestion of Frederick et al. (2002, p. 382), our method applies the binary lottery payment approach first used by Roth and Malouf (1979) in studying bilateral bargaining. We measure how much higher the probability of winning a fixed prize must be in order to delay consumption. The advantage of this method is that individual discount rates can be obtained without knowledge of risk attitude or parametric assumptions about the form 
of the utility function.

We compare our "curvature free" elicitation method to the Andersen et al. (2008) double elicitation technique in which the utility function and discount rates are jointly estimated. We conduct a laboratory experiment to perform a within-subjects comparison of discount rates from these two methods and find consistent results, which is reassuring given the wide range of estimates in the literature. In addition, the estimated discount rates in our study are "plausibly low," in contrast to the vast majority of other discount rate studies. Average discount rates are estimated to be 12.2 percent using our probability discounting elicitation compared to 14.1 percent using joint estimation, and confidence intervals substantially overlap. We find our participants to be risk averse on average, and failing to allow for these non-linear preferences substantially increases the estimated discount rate to 55.5 percent. We consider sensitivity to background consumption and find the jointly estimated discount rates increase modestly as background consumption is increased, while the results from our method are invariant by design. We also consider how our approach is a affected by relaxing the assumption of linearity in the probabilities, but empirically we find little evidence of probability weighting over the range of probabilities used in our experiment.

At the individual level, we find a substantial portion of participants are willing to defer consumption when offered a modest increase in probability of future payment, indicating a very low discount rate. We conduct a second experiment to explore the robustness of this finding and to obtain a within-subjects measure of the sensitivity of the discount rate to both the horizon and the front-end delay. In all treatments, we continue to find a substantial number of very patient participants. We also find evidence in favor of present bias rather than constant time preference.

In Section 2 below we describe an expected utility model with exponential discounting and illustrate our strategy of eliciting time preferences by varying probabilities rather than payoffs. To compare our method with the joint estimation method, we conduct a within-subjects experiment with real-valued payoffs using both methods, as presented in Section 3. In Section 4, we describe our data, report results from maximum likelihood estimation, and present sensitivity tests. Next, in Section 5, we present a second experiment to measure sensitivity of time preferences to the length of the front-end delay and the time horizon. Section 6 concludes.

\section{Theoretical Considerations}

We begin by assuming exponential discounting and an additively-separable inter-temporal utility function. In the typical discount rate model, an individual decides between option $A$ which yields extra income $M_{t}$ at time $t$ and option $B$ which yields $M_{t+\tau}$ at time $t+\tau$ by choosing the option with the larger present value. 
We can express these present values as

$$
P V_{A}=\left(\frac{1}{1+\delta}\right)^{t} U\left(\omega+M_{t}\right)+\left(\frac{1}{1+\delta}\right)^{t+\tau} U(\omega)
$$

and

$$
P V_{B}=\left(\frac{1}{1+\delta}\right)^{t} U(\omega)+\left(\frac{1}{1+\delta}\right)^{t+\tau} U\left(\omega+M_{t+\tau}\right)
$$

where $\omega$ is the time invariant amount of background consumption, $\delta$ is the discount rate, and $U(\cdot)$ is the per-period expected utility function. By equating the present value expressions in Equations 1 and 2, we create the following indifference condition

$$
U\left(\omega+M_{t}\right)+\left(\frac{1}{1+\delta}\right)^{\tau} U(\omega)=U(\omega)+\left(\frac{1}{1+\delta}\right)^{\tau} U\left(\omega+M_{t+\tau}\right)
$$

and can now solve for the discount rate $\delta$. If we further assume the utility function is linear in $\omega$ (as most discount rate studies do) this equation reduces to

$$
M_{t}=\left(\frac{1}{1+\delta}\right)^{\tau} M_{t+\tau}
$$

Equation 4 has been the basis for many previous time preference studies. If, however, preferences are not linear, then Equations 3 and 4 clearly are not the same. Any analysis incorrectly assuming linearity and applying Equation 4 will yield upwardly-biased discount rate estimates. To better illustrate this bias, consider a person who is indifferent between $\$ 1$ now and $\$ 2$ in one year. This indifference condition implies an annual discount rate of 100 percent over monetary amounts. However, concave preferences imply a diminishing marginal utility of money, and so the utility of $\$ 2$ in one year is actually less than twice the utility of $\$ 1$ now. This, in turn, results in an annual discount rate over utility values of less than 100 percent.

One solution to this upward bias of discount rate estimates is to obtain an estimate of the curvature of the utility function and then apply it to Equation 3. An alternative solution that is the focus of this paper is to apply the binary lottery payoff procedure first introduced by Roth and Malouf (1979) to the elicitation of discount rates.

Continuing with Equation 3, we now hold the amount of extra income constant $\left(M_{t}=M_{t+\tau}=M\right)$ and instead vary the probability that the payment is made. Let $p_{t}$ be the probability of receiving extra income $M$ at time $t$ and $p_{t+\tau}$ be the probability of receiving extra income at time $t+\tau$. An individual is indifferent 
between these two options if

$$
\begin{aligned}
& p_{t} U(\omega+M)+\left(1-p_{t}\right) U(\omega)+\left(\frac{1}{1+\delta}\right)^{\tau} U(\omega)= \\
& U(\omega)+\left(\frac{1}{1+\delta}\right)^{\tau}\left[p_{t+\tau} U(\omega+M)+\left(1-p_{t+\tau}\right) U(\omega)\right] .
\end{aligned}
$$

Without loss of generality, we let $U(\omega)=0$ and $U(\omega+M)=1$, and Equation 5 reduces to

$$
p_{t}=\left(\frac{1}{1+\delta}\right)^{\tau} p_{t+\tau}
$$

This expression now provides us an approach to estimate discount rates without having to parameterize and estimate the utility function. In Section 3.1 we develop a simple elicitation procedure for individual discount rates in a manner similar to the widely-used risk aversion elicitation procedure of Holt and Laury (2002). Of course, this approach maintains the expected utility assumption that requires linearity in the objective probabilities. ${ }^{2}$ Alternative assumptions about preferences, such as cumulative prospect theory, allow for probability weighting. We address this possibility in Section 2.4 and empirically in Section 4.3. We also consider consumption smoothing, background consumption, and non-exponential discounting.

\subsection{Consumption Smoothing}

When evaluating intertemporal consumption choices, it seems unduly restrictive to assume away consumption smoothing. Individuals may prefer to spread the consumption of $M$ over several periods. We consider the dual-self model of impulse control proposed by Fudenberg and Levine (2006) and introduced into the context of discounting by Andersen et al. (2008). This model assumes individuals succumb to temptation for immediate gratification when offered short-term gains but are able to plan and smooth consumption when offered gains over a longer term. To apply the dual-self model, we assume that $t$ is sufficiently far in the future that the short-run impulsive "self" is not involved in the decision. ${ }^{3}$ Further, we assume that extra income is smoothed evenly over $\eta$ time periods. Given these assumptions, we rewrite Equation 5 as

$$
\begin{aligned}
p_{t} \sum_{k=0}^{\eta-1} & \left(\frac{1}{1+\delta}\right)^{k} U\left(\omega+\frac{M}{\eta}\right)+\left(1-p_{t}\right) \sum_{k=0}^{\eta-1}\left(\frac{1}{1+\delta}\right)^{k} U(\omega)+\left(\frac{1}{1+\delta}\right)^{\eta} \sum_{k=0}^{\tau-1}\left(\frac{1}{1+\delta}\right)^{k} U(\omega)= \\
& \sum_{k=0}^{\tau-1}\left(\frac{1}{1+\delta}\right)^{k} U(\omega)+\left(\frac{1}{1+\delta}\right)^{\tau}\left[p_{t+\tau} \sum_{k=0}^{\eta-1}\left(\frac{1}{1+\delta}\right)^{k} U\left(\omega+\frac{M}{\eta}\right)+\left(1-p_{t+\tau}\right) \sum_{k=0}^{\eta-1}\left(\frac{1}{1+\delta}\right)^{k} U(\omega)\right] .
\end{aligned}
$$

\footnotetext{
${ }^{2}$ Note that our approach does not require that Equation 6 holds for all combinations of $p_{t}$ and $p_{t+\tau}$. We can cover a broad range of discount rates ( 0 to 347 percent) by varying p between 0.5 and .65 , thus allowing us to avoid extreme probabilities where probability weighting has been shown to be most severe.

${ }^{3}$ We chose our experimental implementation to satisfy this assumption: all payments are made either three or twelve weeks in the future.
} 
We assign $U(\omega)=0$ and Equation 7 simplifies to

$$
p_{t} \sum_{k=0}^{\eta-1}\left(\frac{1}{1+\delta}\right)^{k} U\left(\omega+\frac{M}{\eta}\right)=\left(\frac{1}{1+\delta}\right)^{\tau} p_{t+\tau} \sum_{k=0}^{\eta-1}\left(\frac{1}{1+\delta}\right)^{k} U\left(\omega+\frac{M}{\eta}\right)
$$

We next divide both sides of this expression by $\sum_{k=0}^{\eta-1}\left(\frac{1}{1+\delta}\right)^{k} U\left(\omega+\frac{M}{\eta}\right)$, and see the expression simplifies to Equation 6. Thus, consumption smoothing - as long as consumption is even - does not alter our probability discounting approach for eliciting time preference.

\subsection{Background Consumption}

In our model, we assume background consumption $\omega$ to be constant over the time frame we analyze. This assumption seems reasonable given our experimental design: all payments were made at either three or twelve weeks with all payments made during a single semester. ${ }^{4}$ Given constant background consumption, we see from Equation 6 that our procedure is invariant to the level of background consumption. In contrast, elicitation techniques that require estimating and controlling for the curvature of the utility function (e.g. Andersen et al. (2008) and Andreoni and Sprenger (2012)) are sensitive to the level of background consumption. We report a sensitivity analysis of such estimation to changing levels of background consumption in Section 4.2 .

\subsection{Non-exponential Discounting}

We assume exponential discounting, but hyperbolic discounting models can also be considered. For example, Keller and Strazzera (2002) apply the hyperbolic model axiomatized by Harvey (1986) to obtain the hyperbolic equivalent of Equation 4 in which $\left(\frac{1}{1+\tau}\right)^{\delta^{\prime}}$ replaces $\left(\frac{1}{1+\delta}\right)^{\tau}$. Unless utility is linear in wealth, this approach yields upwardly biased estimates of hyperbolic discount rates. Our approach combined with the assumption of hyperbolic discounting yields unbiased estimates of $\delta^{\prime}$.

\subsection{Preferences with Non-linear Probabilities}

We now consider how our approach is affected if we relax the assumption of linearity in the probabilities by allowing probability weighting. Suppose we assume that cumulative prospect theory (hereafter CPT) (Tversky and Kahneman, 1992) characterizes preferences rather than expected utility theory. Following CPT, we assume that $w(p)$ is the probability weighting function and $V_{+}(m)$ is the value function for gains,

\footnotetext{
${ }^{4}$ Longer time horizons introduce the possibility of background consumption changing over time, which when not accounted for will bias discount rate estimates. See Noor (2009) for a discussion.
} 
with $V_{+}(0)=0$ and $V_{+}(M)$ increasing in $M$. CPT does not provide guidance about how to evaluate prospects that offer both immediate and future payouts, so we maintain our assumption of exponential discounting for future values and temporal separability. Given these assumptions, Equation 5 becomes

$$
\begin{aligned}
w\left(p_{t}\right) V_{+}(M)+\left(1-w\left(p_{t}\right)\right) V_{+}(0)+ & \left(\frac{1}{1+\delta}\right)^{\tau} V_{+}(0)= \\
& V_{+}(0)+\left(\frac{1}{1+\delta}\right)^{\tau}\left[w\left(p_{t+\tau}\right) V_{+}(M)+\left(1-w\left(p_{t+\tau}\right)\right) V_{+}(0)\right] .
\end{aligned}
$$

More intuitively, because $V_{+}(0)=0$, this expression becomes

$$
w\left(p_{t}\right) V_{+}(M)=\left(\frac{1}{1+\delta}\right)^{\tau} w\left(p_{t+\tau}\right) V_{+}(M)
$$

which shows that an individual is indifferent when the probability-weighted value of winning $M$ at time $t$ is equal to the discounted probability-weighted value of winning $M$ at time $\tau$. Finally, dividing both sides by $V_{+}(M)>0$ gives

$$
w\left(p_{t}\right)=\left(\frac{1}{1+\delta}\right)^{\tau} w\left(p_{t+\tau}\right) .
$$

This expression is our CPT analogue to Equation 6 where the probabilities have been replaced with the weighted probabilities. The advantage of using this expression to estimate discount rate is that we can avoid estimating the value function $V_{+}(m)$. We will, however, need to estimate $w(p)$, and that will require additional parametric assumptions. For example, we could assume Prelec's (1998) probability weighting function $w(p)=e^{-(-\ln p)^{\gamma}}$ and would then need to jointly estimate $\gamma$ and $\delta$. It is also worth noting that the importance of neglecting probability weighting will depend on the ratio $w\left(p_{t}\right) / w\left(p_{t+\tau}\right)$, and this will vary over the range of probabilities used in the elicitation. In our case, we have set $p_{t}=0.5$ and $0.5<p_{t+\tau}<0.67$. If $w(p)$ is well approximated by a ray through the origin over this range - that is, if there exists $\alpha$ such that $w(p)=\alpha p$ over the required range for $p$ - then ignoring probability weighting will not appreciably bias our estimates.

\section{Experimental Design}

Our experiments are designed to elicit discount rates using the binary lottery payment approach in which we vary the probability (rather than the prize) over time. We call this the probability task. We also provide a within-subjects comparison of our "curvature-free" approach to the alternative of jointly estimating the utility function and discount rates using the joint elicitation procedure of Andersen et al. (2008). Given the 
huge variation of elicited discount rates in the literature, even among studies that adjust for curvature, it would be reassuring to find that two different methods yield similar results when applied in similar conditions. We begin by describing our probability discount rate elicitation task and then describe the two tasks we use as inputs for the joint elicitation comparison.

\subsection{Probability Discount Rate Elicitation}

In the Probability Discount Rate Task (Task P), subjects choose between a "Sooner" lottery to be played at time $t$ and "Later" lottery with the same prize but greater chances of paying off. ${ }^{5}$ The Sooner lottery offers a 50 percent chance of earning $\$ 200$ in 3 weeks. The later lottery offers the same cash prize of $\$ 200$, but the prize is not paid until 12 weeks after the date of the experimental session. Each subject is presented with 20 of these paired choices in a multiple price list format. Table 1 (which is not shown to subjects) shows the choices presented to the subjects, along with associated annual effective interest rates (AEIR) and implied discount rate ranges. ${ }^{6}$ In the first Decision row, the Later lottery has the same chances of paying as the Sooner option, corresponding to a 0 percent interest rate. Moving down the table, the probability of winning with the Later option increases indicating a higher expected rate of return for waiting the additional 9 weeks. In the last row, Decision 20, the choice is between a 50/50 chance of winning $\$ 200$ in 3 weeks and a 64.7 percent chance of winning $\$ 200$ in 12 weeks. In our experiment, interest is compounded daily between 3 and 12 weeks, resulting in an AEIR of between 0 and 346.79 percent across the 20 decisions.

The point at which the subject switches from choosing the Sooner to the Later option reveals the interest rate the subject must receive in order to be willing to wait for the later lottery. For example, in Decision 15, the subject must choose between 50 percent chance of receiving $\$ 200$ in 3 weeks and an 52.7 percent chance of winning $\$ 200$ in 12 weeks. In this Decision, the increase in expected payoff from the Sooner to the Later option represents an annual effective interest rate of 34.97 percent with interest accruing starting 3 weeks from the experiment date (when the Sooner option pays out) until 12 weeks from the experiment date (when the Later option pays out). Participants who switch from the Sooner option to the Later option in Decision 15 reveal that their discount rates is between 28.39 and 34.97 percent.

In designing the decision choices in the $\mathrm{P}$ Task, we turned to the literature to form our priors about the key range of discount rates to explore. Estimates that ignore the curvature of the utility function are likely to be upwardly biased, and the curvature-corrected estimates of Andersen et al. (2008) are on the low end of the scale. To allow for very low discount rates to be revealed in our decision task, we begin with a zero AEIR and then increase the chances of winning with the Later option by small amounts. We include the

\footnotetext{
${ }^{5}$ In subject instructions and decision sheets, the Sooner option is referred to as Option A and the Later option as Option B.

${ }^{6}$ The actual decision tables presented to subjects are shown in Appendix A.
} 
Table 1: Probability discount rate elicitation (P Task) choices and implied ranges of discount rates

\begin{tabular}{ccccc}
\hline & $\begin{array}{c}\text { Chance of } \\
\$ 200 \text { in } \\
3 \text { weeks } \\
\text { (percent) }\end{array}$ & $\begin{array}{c}\text { Chance of } \\
\$ 200 \text { in } \\
12 \text { weeks } \\
\text { (percent) }\end{array}$ & $\begin{array}{c}\text { Annual } \\
\text { effective } \\
\text { interest rate } \\
\text { (percent) }\end{array}$ & $\begin{array}{c}\text { Implied discount rate } \\
\text { range if switching } \\
\text { in this row } \\
\text { (percent) }\end{array}$ \\
\hline 1 & 50.0 & 50.0 & 0.00 & $\delta \leq 0.00$ \\
2 & 50.0 & 50.1 & 1.01 & $0.00 \leq \delta \leq 1.01$ \\
3 & 50.0 & 50.2 & 2.02 & $1.01 \leq \delta \leq 2.02$ \\
4 & 50.0 & 50.4 & 4.08 & $2.02 \leq \delta \leq 4.08$ \\
5 & 50.0 & 50.5 & 6.18 & $4.08 \leq \delta \leq 6.18$ \\
6 & 50.0 & 50.7 & 8.33 & $6.18 \leq \delta \leq 8.33$ \\
7 & 50.0 & 50.9 & 10.52 & $8.33 \leq \delta \leq 10.52$ \\
8 & 50.0 & 51.1 & 12.75 & $10.52 \leq \delta \leq 12.75$ \\
9 & 50.0 & 51.2 & 15.02 & $12.75 \leq \delta \leq 15.02$ \\
10 & 50.0 & 51.4 & 17.35 & $15.02 \leq \delta \leq 17.35$ \\
11 & 50.0 & 51.6 & 19.72 & $17.35 \leq \delta \leq 19.72$ \\
12 & 50.0 & 51.8 & 22.13 & $19.72 \leq \delta \leq 22.13$ \\
13 & 50.0 & 52.0 & 25.22 & $22.13 \leq \delta \leq 25.22$ \\
14 & 50.0 & 52.2 & 28.39 & $25.22 \leq \delta \leq 28.39$ \\
15 & 50.0 & 52.7 & 34.97 & $28.39 \leq \delta \leq 34.97$ \\
16 & 50.0 & 53.6 & 49.15 & $34.97 \leq \delta \leq 49.15$ \\
17 & 50.0 & 54.5 & 64.82 & $49.15 \leq \delta \leq 64.82$ \\
18 & 50.0 & 56.9 & 111.54 & $64.82 \leq \delta \leq 111.54$ \\
19 & 50.0 & 59.4 & 171.46 & $111.54 \leq \delta \leq 171.46$ \\
20 & 50.0 & 64.7 & 346.79 & $171.46 \leq \delta \leq 346.79$ \\
\hline
\end{tabular}

zero interest rate choice in the first Decision Row as a check on whether participants understand the choices (or perhaps are choosing to wait as a form of enforced savings). While we hypothesize that some individual discount rates may be very low, we cannot rule out the possibility of shockingly high discount rates that have been reported in the literature. To allow for a sufficiently broad range of discount rates in our task without confronting subjects with an unwieldy number of decision rows, we gradually increase the increment between AEIRs for the higher decision rows.

The payment date for both the Sooner and the Later options are set in the future. This front-end delay was introduced by Coller and Williams (1999), and it is used to control for transaction costs associated with returning for payment at a later date and any uncertainty about the reliability of receiving payment introduced due to the time delay. In our discount rate tasks, subjects choose between receiving payment in either 3 or 12 weeks. Our subjects were university students and we believe it is important that subjects receive all payments during the course of one semester. If some subjects expect to graduate or leave the University between the Sooner and Later payment dates, this would introduce differences in transactions costs and possibly differences in background consumption between the two payment dates. Therefore the longest time horizon we could reasonably use was 12 weeks. 


\subsection{Joint Elicitation}

For our joint elicitation procedure, we adapt the procedures described in Andersen et al. (2008). Utility curvature is measured using the Holt and Laury (2002) risk preference measure (Task R), and discount rates over dollar amounts are measured using the Coller and Williams (1999) time preference measure (Task D). Andersen et al. typically presented their subjects with 10 binary decisions per task; however, to be consistent with our Task P design, we present our subjects with 20 binary decisions in each task.

In the dollar discount rate task (Task D) subjects are shown 20 paired choices between receiving a sum of money in three weeks and receiving a typically larger sum of money in 12 weeks (see the instructions and decision table in Appendix A). For each Decision row, the subject is asked to choose between a Sooner and Later option ${ }^{7}$; time delays of 3 and 12 weeks are used for consistency with the P-Task decisions. In all 20 decisions, the Sooner option entails receiving $\$ 200$ in 3 weeks. For the Later option, the amount of money the subject would receive in 12 weeks starts at $\$ 200$ in Decision 1 and increases to $\$ 258.96$ in Decision 20. Subjects are also provided the annual interest rates and annual effective interest rates for each choice in Task D. Coller and Williams argued for including this information because it was available in many naturally-occurring situations in which individuals make decisions about whether to borrow or lend. ${ }^{8}$ Table 2 summarizes the 20 choices and shows the AEIR associated with each choice. The AEIRs for each Decision row in Task $\mathrm{P}$ corresponds to that of the same row in Task $\mathrm{D}$. The correspondence between the AEIR rows for the P Task and the D Task might be a problem if participants tend to switch at the same row across tasks. Note that under our hypothesis that most participants are risk averse, we predict that participants will switch to the Later option at an earlier row in the $\mathrm{P}$ Task than the $\mathrm{D}$ task. Thus, a simple switching heuristic between decision-making tasks (e.g., always switching in the fifth row) would bias decisions away from our expected finding.

The risk preference measurement task (Task R) follows procedures first introduced by Holt and Laury (2002), except that each subject is presented with 20 decisions instead of 10 . Each subject is asked to make a choice between two paired lotteries, labeled Option A and Option B. Option A represents the "safe" lottery in that there is a relatively small difference between the high and low outcome. Option B represents the "risky" lottery because there is a relatively large difference between the high and low outcome. Table 3 summarizes the choices given to the subjects, although the range of implied risk aversion was not shown to subjects. Holt and Laury demonstrated that when the payoff scale is increased, the observed risk aversion

\footnotetext{
${ }^{7}$ As in Task $\mathrm{P}$, in subject instructions and decision sheets these were labeled Option A and Option B

${ }^{8}$ Our pilot experiments had sessions with and without the AEIR information. Excluding this information did not appear to have substantial affect on the pilot results. Ultimately we decided to exclude the AEIR from the P-Task because there is no naturally-occurring counterpart for expressing probabilities as interest rates. Coller and Williams (1999) first introduced the AEIR information to the discount rate task and found that including the AEIR led to lower discount rate estimates and residual variance.
} 
Table 2: Dollar discount rate elicitation (D Task) choices and implied ranges of discount rates

\begin{tabular}{|c|c|c|c|c|}
\hline Row & $\begin{array}{l}\text { Amount } \\
\text { paid in } \\
3 \text { weeks } \\
\text { (dollars) }\end{array}$ & $\begin{array}{l}\text { Amount } \\
\text { paid in } \\
12 \text { weeks } \\
\text { (dollars) }\end{array}$ & $\begin{array}{c}\text { Annual } \\
\text { effective } \\
\text { interest rate } \\
\text { (percent) }\end{array}$ & $\begin{array}{l}\text { Implied discount rate } \\
\text { range if switching } \\
\text { in this row } \\
\text { (percent) }^{1}\end{array}$ \\
\hline 1 & 200.00 & 200.00 & 0.00 & $\delta \leq 0.00$ \\
\hline 2 & 200.00 & 200.35 & 1.01 & $0.00 \leq \delta \leq 1.01$ \\
\hline 3 & 200.00 & 200.69 & 2.02 & $1.01 \leq \delta \leq 2.02$ \\
\hline 4 & 200.00 & 201.39 & 4.08 & $2.02 \leq \delta \leq 4.08$ \\
\hline 5 & 200.00 & 202.08 & 6.18 & $4.08 \leq \delta \leq 6.18$ \\
\hline 6 & 200.00 & 202.78 & 8.33 & $6.18 \leq \delta \leq 8.33$ \\
\hline 7 & 200.00 & 203.48 & 10.52 & $8.33 \leq \delta \leq 10.52$ \\
\hline 8 & 200.00 & 204.18 & 12.75 & $10.52 \leq \delta \leq 12.75$ \\
\hline 9 & 200.00 & 204.89 & 15.02 & $12.75 \leq \delta \leq 15.02$ \\
\hline 10 & 200.00 & 205.60 & 17.35 & $15.02 \leq \delta \leq 17.35$ \\
\hline 11 & 200.00 & 206.31 & 19.72 & $17.35 \leq \delta \leq 19.72$ \\
\hline 12 & 200.00 & 207.02 & 22.13 & $19.72 \leq \delta \leq 22.13$ \\
\hline 13 & 200.00 & 207.92 & 25.22 & $22.13 \leq \delta \leq 25.22$ \\
\hline 14 & 200.00 & 208.82 & 28.39 & $25.22 \leq \delta \leq 28.39$ \\
\hline 15 & 200.00 & 210.62 & 34.97 & $28.39 \leq \delta \leq 34.97$ \\
\hline 16 & 200.00 & 214.29 & 49.15 & $34.97 \leq \delta \leq 49.15$ \\
\hline 17 & 200.00 & 218.01 & 64.82 & $49.15 \leq \delta \leq 64.82$ \\
\hline 18 & 200.00 & 227.61 & 111.54 & $64.82 \leq \delta \leq 111.54$ \\
\hline 19 & 200.00 & 237.62 & 171.46 & $111.54 \leq \delta \leq 171.46$ \\
\hline 20 & 200.00 & 258.96 & 346.79 & $171.46 \leq \delta \leq 346.79$ \\
\hline
\end{tabular}

coefficient increases as well. Therefore, we use monetary outcomes for these lotteries such that the expected value of the lotteries are (on average) at a scale consistent with the monetary outcomes in the discount rate task.

Option A involves a chance to receive either $\$ 180$ or $\$ 144$, and Option B involves a chance to receive either $\$ 346.50$ or $\$ 9 .^{9}$ The chance of receiving the higher-payment outcome starts at 5 percent in Decision 1, and increases to 100 percent in Decision 20 (so in Decision 20 the choice is between $\$ 180$ and $\$ 346.50$ with certainty). The point at which the subject switches from Option A to Option B is used to infer an interval estimate of the subject's coefficient of risk aversion. A risk neutral subject will choose Option A as long as its expected value exceeds that of Option B, and then shift to Option B. In this task, the risk neutral prediction is to choose Option A for the first 8 Decision rows, and then to switch to Option B. A risk seeking person would choose Option A for fewer than the first 8 Decision rows, and a risk averse person would choose Option A for more than the first 8 Decision rows.

\footnotetext{
${ }^{9}$ These are the same payment levels used by Holt and Laury (2002) in their highest payment treatment.
} 
Table 3: Risk preference elicitation (R Task) choices and implied CRRA ranges

\begin{tabular}{|c|c|c|c|c|c|}
\hline \multirow[b]{2}{*}{ Row } & \multicolumn{2}{|c|}{ Lottery A } & \multicolumn{2}{|c|}{ Lottery B } & \multirow[b]{2}{*}{$\begin{array}{l}\text { Range of relative risk } \\
\text { aversion for } u(x)=\frac{x^{1-r}}{1-r} \\
\text { if switching in this row }\end{array}$} \\
\hline & $\begin{array}{l}\text { chance } \\
\text { of } \$ 180 \\
\text { (percent) }\end{array}$ & $\begin{array}{c}\text { chance } \\
\text { of } \$ 144 \\
\text { (percent) }\end{array}$ & $\begin{array}{c}\text { chance } \\
\text { of } \$ 346.50 \\
\text { (percent) }\end{array}$ & $\begin{array}{c}\text { chance } \\
\text { of } \$ 9 \\
\text { (percent) }\end{array}$ & \\
\hline 1 & 5 & 95 & 5 & 95 & $r \leq-2.48$ \\
\hline 2 & 10 & 90 & 10 & 90 & $-2.48 \leq r \leq-1.71$ \\
\hline 3 & 15 & 85 & 15 & 85 & $-1.71 \leq r \leq-1.27$ \\
\hline 4 & 20 & 80 & 20 & 80 & $-1.27 \leq r \leq-0.95$ \\
\hline 5 & 25 & 75 & 25 & 75 & $-0.95 \leq r \leq-0.70$ \\
\hline 6 & 30 & 70 & 30 & 70 & $-0.70 \leq r \leq-0.49$ \\
\hline 7 & 35 & 65 & 35 & 65 & $-0.49 \leq r \leq-0.31$ \\
\hline 8 & 40 & 60 & 40 & 60 & $-0.31 \leq r \leq-0.14$ \\
\hline 9 & 45 & 55 & 45 & 55 & $-0.14 \leq r \leq 0.01$ \\
\hline 10 & 50 & 50 & 50 & 50 & $0.01 \leq r \leq 0.15$ \\
\hline 11 & 55 & 45 & 55 & 45 & $0.15 \leq r \leq 0.28$ \\
\hline 12 & 60 & 40 & 60 & 40 & $0.28 \leq r \leq 0.41$ \\
\hline 13 & 65 & 35 & 65 & 35 & $0.41 \leq r \leq 0.54$ \\
\hline 14 & 70 & 30 & 70 & 30 & $0.54 \leq r \leq 0.68$ \\
\hline 15 & 75 & 25 & 75 & 25 & $0.68 \leq r \leq 0.82$ \\
\hline 16 & 80 & 20 & 80 & 20 & $0.82 \leq r \leq 0.97$ \\
\hline 17 & 85 & 15 & 85 & 15 & $0.97 \leq r \leq 1.15$ \\
\hline 18 & 90 & 10 & 90 & 10 & $1.15 \leq r \leq 1.37$ \\
\hline 19 & 95 & 5 & 95 & 5 & $1.37 \leq r \leq 1.68$ \\
\hline 20 & 100 & 0 & 100 & 0 & $1.68 \leq r \leq 2.25$ \\
\hline
\end{tabular}

\subsection{Experiment Procedures}

A total of 103 subjects participated in six experimental sessions at Georgia State University between September 14 and September 17, 2009. Each subject completed three decision tasks: a probability discount rate choice task (Task P), a dollar discount rate choice task (Task D), and a risk preference measurement task (Task R). The discount rate tasks were always given first and the order of those tasks was varied by session. In three sessions, 51 subjects faced Task P, then Task D, and then Task R. In the remaining three sessions, 52 subjects faced Task D, then Task $\mathrm{P}$, and then Task R.

After subjects had completed all three decision tasks, they were taken individually to a private room to determine the outcomes (and earnings) from each of the three tasks. In each task, only one of the decision rows was used in the final payment phase of the experiment. In the instructions subjects were told: "Even though you will make twenty Decisions, only one of these will end up possibly affecting your earnings, but you will not know in advance which Decision will be used. Each Decision has an equal chance of being used for payment."

After the binding decision was determined, earnings were determined for the task. In the standard discount rate task over changing dollar amounts, this was simply the dollar amount determined by their choice of the Sooner option or the Later option in the binding decision. Using Decision 15 as an example, if 
the subject chose the Sooner option, the outcome would be $\$ 200$ in 3 weeks; if the subject chose the Later option, the outcome would be $\$ 210.62$ in 12 weeks.

In the probability discounting task, after the binding decision was selected a die throw was used to determine whether the outcome was $\$ 200$ or nothing. Using Decision 15 as an example once more, if the subject chose the Sooner option, there was a 50 percent chance that the monetary outcome would be $\$ 200$; if the subject chose the Later option, there was a 52.7 percent chance that the monetary outcome would be \$200. As described in the subject instructions, three 10-sided die were used to determine the outcome: a red die was used to determine the hundreds digit, a white die was used to determine the tens digit, and a blue die was used to determine the ones digit. For example, if the die-roll was a 3 on the red die, a 7 on the white die, and a 6 on the blue die the outcome was 376 .

In the risk preference measurement task, after the binding decision was selected a 20 -sided die was used to determine the monetary outcome. Using Decision 15 as an example, if the subject chose Option A and the die throw was between 1 and 15 , the outcome would be $\$ 180$, otherwise the outcome would be $\$ 144$; if the subject chose Option B and the die throw was between 1 and 15, the outcome would be $\$ 346.40$, otherwise the outcome would be $\$ 9$.

The final payment phase determined whether the subject was paid the monetary outcome in one or more of the three tasks. There was a 10-percent chance that the subject would be paid in the standard dollar discount rate task and in the risk preference measurement task. There was a 20-percent chance that the subject would be paid in the binary-lottery discount rate task. ${ }^{10}$

Subjects' earnings in the experiment were the sum of the earnings from the three decision-making tasks plus a $\$ 20$ participation payment (because only 10 percent of subjects on average receive payment in any task, the participation payment was set higher than usual: $\$ 5$ for arriving to the experiment on time plus another $\$ 5$ for each of the three decision-making tasks). Subjects received the participation payment and any earnings from the risk preference measurement task in cash before leaving the experimental session. Subjects who received payment from either discount rate tasks received a certificate for payment that could be redeemed in either 3 or 12 weeks. Subjects who were paid for an Option A choice received payment during the week of October 5, and subjects who were paid for an Option B choice received payment during the week of December 7 .

Demographic characteristics of our subjects are presented in Table 4. The mean age of the participants was 21.77 years, ranging from 18 to 47 in the DPR treatment, and from 18 to 46 in the PDR treatment

\footnotetext{
${ }^{10}$ This equates the expected value of the payment in the standard and binary-lottery discount rate tasks, as the baseline probability of payment was only 50 percent in Task P, but 100 percent in the two other tasks. Randomly determining whether a subject receives payment is used for consistency with earlier discount rate studies, including Coller and Williams (1999) and Andersen et al. (2008).
} 
order. Subjects were about equally divided between male and female. The racial makeup of our subject pool is more diverse than most. About 43 percent reported being white, 35 percent black, and 13 percent Asian. The demographics appear to be well balanced between sessions. Sorting by treatment order, our analysis reveals no significant difference by task order, so we combine the the data for the analysis reported here.

Table 4: Demographic characteristics.

\begin{tabular}{cccc}
\hline Demographic & All & Order & Order \\
Characteristic & Participants & DPR & PDR \\
\hline Average Age & 21.77 & 21.78 & 21.76 \\
Percent Male & 51.4 & 49 & 54 \\
Percent White & 43 & 41 & 44 \\
Percent Black & 35 & 35 & 35 \\
Percent Asian & 13 & 12 & 13 \\
Percent Raised in US & 92 & 92 & 92 \\
Percent Freshman & 10 & 4 & 15 \\
Percent Sophomore & 31 & 33 & 29 \\
Percent Junior & 42 & 45 & 38 \\
Percent Senior & 17 & 16 & 17 \\
Average GPA & 3.23 & 3.19 & 3.27 \\
\hline
\end{tabular}

\section{Results}

First, we turn to an overview of our data and then present results from maximum likelihood estimation. Figure 1 displays the proportion of subjects selecting the Sooner payment option (payment in 3 weeks) in each of the 20 decisions. Recall that the AEIR increases as the subject moves down the decision sheet so that a greater number of Sooner choices implies a higher discount rate. Lines with square markers show the data for Task D (the standard dollar discount rate task), and lines with circle markers show the data for Task $\mathrm{P}$ (the binary lottery payment discount rate task). We see that participants appear much more impatient (a much higher proportion of subjects choose the Sooner option in each decision) when given the standard dollar discounting task than when given the probability discounting task. If subjects are risk neutral (that is, if utility is linear in wealth), then we expect to find the same discount rates in each task. Instead, we see that discount rates are higher in Task D than in Task P. For example, in Decision 6, 80 percent of subjects choose the Sooner option in Task D, compared to 50 percent of the same subjects who choose the Sooner option in Task P. This pattern is what we expect if participants have utility that is concave in wealth. In this case, we expect that the discount rate from the standard dollar task will overstate the true discount rate.

Based on the pattern of responses from the two discount rate tasks, we expect to find that the average participant is our study is risk averse. Table 5 shows the average responses for each task and confirms our 


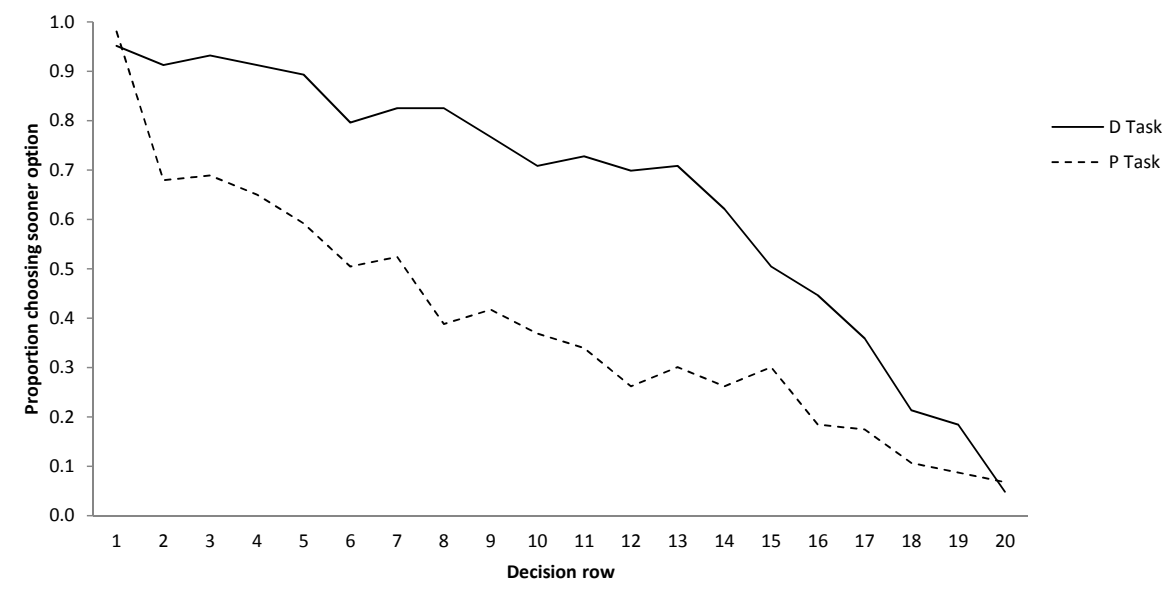

Figure 1: Proportion of subjects selecting the Sooner option (option A) by decision row and treatment.

Table 5: Number of Safer (Task R) and Sooner (Task P and D) Choices in each Task

\begin{tabular}{cccc}
\hline & & & Standard \\
Task & Mean & Median & Deviation \\
\hline Risk aversion (Task R) & 13.24 & 14 & 3.47 \\
Standard dollar discounting (task D) & 13.04 & 14 & 4.92 \\
Binary lottery payment discounting (task P) & 7.88 & 8 & 5.60 \\
\hline
\end{tabular}

hypothesis that the average participant has concave rather than linear preferences. In the risk aversion task, participants choose Option A, the "safe" choice that offers a lower variance in payoffs, for an average of 13 decisions. The risk neutral prediction is to choose Option A for the first 8 Decision rows, and then to switch to Option B. These results indicate a coefficient of relative risk aversion in the range of 0.41 to 0.54 . These results are also consistent with the degree of risk aversion found by Holt and Laury (2002) for similar stakes.

Given risk averse participants, we expect to find a difference in average discount rates in Task D and Task P. Indeed, in Task D, subjects chose the Sooner option for an average of 13.0 decisions, compared to 7.9 Sooner choices for Task P. Because subjects made choices in both tasks, we can test for differences in the central tendency of choices using the nonparametric Wilcoxon Signed Ranks Test. This is a relatively powerful test of the differences between the two treatments that uses both the sign of the difference between a subject's choices in the two tasks and the size of the difference. The null hypothesis of no difference between the two tasks is rejected at any standard level of confidence.

Turning our attention to those subjects who do not exhibit multiple switch points between the Sooner and Later options, Table 6 shows the portion of participants who switch in each decision row for each task. ${ }^{11}$ In Task $\mathrm{P}$ we see a substantial portion of participants (33.7 percent) chose to switch in Decision 2, the first

\footnotetext{
${ }^{11}$ It is common to exclude multi-switchers from analyses that focus on a single switch point. An advantage of the maximum likelihood estimation that follows is that we can add error terms to the model and include all decisions.
} 
decision that yields a positive rate of interest. ${ }^{12}$ This is consistent with a discount rate between 0 and 1.01 percent. Given contemporaneous market rates of interest,${ }^{13}$ low discount rates are entirely plausible, and yet, rarely seen in the literature on elicited discount rates. When we use the data from Task D, which does not account for the curvature in the utility function, we do not find such low discount rates. Instead we find only a handful of individuals willing to save until the interest rate is at least 6 percent.

Table 6: Distributions of switching behavior across tasks

\begin{tabular}{|c|c|c|c|c|c|}
\hline \multirow[b]{3}{*}{ Row } & \multicolumn{2}{|l|}{ Risk task } & \multicolumn{3}{|c|}{ Discounting Tasks } \\
\hline & \multirow{2}{*}{$\begin{array}{l}\text { Range of relative } \\
\text { risk aversion if } \\
\text { switching in this row }{ }^{1}\end{array}$} & \multirow{2}{*}{$\begin{array}{l}\text { Proportion } \\
\text { switching } \\
\text { in this row } \\
\text { (percent) }^{2}\end{array}$} & \multirow{2}{*}{$\begin{array}{l}\text { Range of discount } \\
\text { rate if switching } \\
\text { in this row } \\
\text { (percent) }^{3}\end{array}$} & \multicolumn{2}{|c|}{$\begin{array}{l}\text { Proportion switching } \\
\text { in this row }\end{array}$} \\
\hline & & & & $\begin{array}{l}\text { Task D } \\
(\text { percent })^{4}\end{array}$ & $\begin{array}{c}\text { Task P } \\
(\text { percent })^{5}\end{array}$ \\
\hline 1 & $r \leq-2.48$ & 0.0 & $\delta \leq 0.00$ & 2.5 & 1.30 \\
\hline 2 & $-2.48 \leq r \leq-1.71$ & 0.0 & $0.00 \leq \delta \leq 1.01$ & 2.5 & 33.77 \\
\hline 3 & $-1.71 \leq r \leq-1.27$ & 0.0 & $1.01 \leq \delta \leq 2.02$ & 0.0 & 2.60 \\
\hline 4 & $-1.27 \leq r \leq-0.95$ & 0.0 & $2.02 \leq \delta \leq 4.08$ & 0.0 & 1.30 \\
\hline 5 & $-0.95 \leq r \leq-0.70$ & 0.0 & $4.08 \leq \delta \leq 6.18$ & 1.2 & 3.90 \\
\hline 6 & $-0.70 \leq r \leq-0.49$ & 0.0 & $6.18 \leq \delta \leq 8.33$ & 4.9 & 7.79 \\
\hline 7 & $-0.49 \leq r \leq-0.31$ & 1.3 & $8.33 \leq \delta \leq 10.52$ & 1.2 & 1.30 \\
\hline 8 & $-0.31 \leq r \leq-0.14$ & 0.0 & $10.52 \leq \delta \leq 12.75$ & 1.2 & 7.79 \\
\hline 9 & $-0.14 \leq r \leq 0.01$ & 1.3 & $12.75 \leq \delta \leq 15.02$ & 3.7 & 1.30 \\
\hline 10 & $0.01 \leq r \leq 0.15$ & 12.5 & $15.02 \leq \delta \leq 17.35$ & 3.7 & 3.90 \\
\hline 11 & $0.15 \leq r \leq 0.28$ & 7.5 & $17.35 \leq \delta \leq 19.72$ & 1.2 & 3.90 \\
\hline 12 & $0.28 \leq r \leq 0.41$ & 3.8 & $19.72 \leq \delta \leq 22.13$ & 3.7 & 5.19 \\
\hline 13 & $0.41 \leq r \leq 0.54$ & 3.8 & $22.13 \leq \delta \leq 25.22$ & 3.7 & 2.60 \\
\hline 14 & $0.54 \leq r \leq 0.68$ & 6.3 & $25.22 \leq \delta \leq 28.39$ & 2.5 & 2.60 \\
\hline 15 & $0.68 \leq r \leq 0.82$ & 16.3 & $28.39 \leq \delta \leq 34.97$ & 12.4 & 1.30 \\
\hline 16 & $0.82 \leq r \leq 0.97$ & 10.0 & $34.97 \leq \delta \leq 49.15$ & 9.9 & 5.19 \\
\hline 17 & $0.97 \leq r \leq 1.15$ & 13.8 & $49.15 \leq \delta \leq 64.82$ & 8.6 & 2.60 \\
\hline 18 & $1.15 \leq r \leq 1.37$ & 5.0 & $64.82 \leq \delta \leq 111.54$ & 17.3 & 6.49 \\
\hline 19 & $1.37 \leq r \leq 1.68$ & 10.0 & $111.54 \leq \delta \leq 171.46$ & 4.9 & 2.60 \\
\hline 20 & $1.68 \leq r \leq 2.25$ & 7.5 & $171.46 \leq \delta \leq 346.79$ & 8.6 & 0.00 \\
\hline \multicolumn{6}{|c|}{${ }^{1}$ Assuming $u(x)=\frac{x^{1-r}}{1-r}$} \\
\hline \multicolumn{6}{|c|}{$\begin{array}{l}2 \text { Including only the } 80 \text { of } 103 \text { subjects who did not multiswitch in } \mathrm{R} \text { Task. One subject always } \\
\text { chose Lottery B implying a risk aversion parameter of at least } 2.25 \text {. } \\
3 \text { These discount rates apply to monetary amounts for the } \mathrm{D} \text { task and to the true discount rates } \\
\text { over utility for the P Task. If risk neutral, then these are the same across tasks. } \\
{ }^{4} \text { Including only the } 81 \text { of } 103 \text { subjects who did not multiswitch in the } \mathrm{D} \text { task. Five subjects always } \\
\text { chose the Sooner option implying a discount rate over money of at least } 346.79 \text { percent. } \\
5 \text { Including only the } 77 \text { of } 103 \text { subjects who did not multiswitch in the } \mathrm{P} \text { task. Two subjects always } \\
\text { chose the Sooner option implying a discount rate of at least } 346.79 \text { percent. }\end{array}$} \\
\hline
\end{tabular}

Overall, our results indicate that using probabilities to elicit discount rates (Task P) reduces the upward bias caused by the assumption of linear utility in the more standard (dollar) discount rate elicitation method.

\footnotetext{
${ }^{12}$ In a pilot experiment with the $\mathrm{P}$ Task that did not include a zero percent interest rate choice (Morgan, 2009), 45.7 percent of participants choose Option B for all decisions implying a discount rate of less than 2.02 percent. The pilot experiments differed in other important dimensions (including lower stakes, shorter time horizon, AEIR provided in some sessions, and conducted at different university); yet, the pilot results are broadly consistent with the findings we report here.

${ }^{13}$ At the time the experiment was conducted, interest rates were quite low. For example, Bankrate.com's weekly survey of banks conducted October 21, 2009, found a yield for one-year CD of only 0.92 percent. http://www.bankrate.com/finance/ cd/national-cd-rate-averages8-134136.aspx
} 
The next section examines this issue more formally and allows a direct comparison of the discount rate elicited in Task $\mathrm{P}$ with the curvature-corrected discount rate obtained via joint-estimation of the parameters of the utility function.

\subsection{Model Estimation}

We now turn to our estimation procedures. First, we describe the likelihood functions for the probability discount rate estimation and the joint estimation. Next, we report the estimation results and consider the sensitivity to changing values of background consumption. And finally, we introduce probability weighting into the estimation to gauge robustness to allowing for preferences that are non-linear in both probabilities and wealth.

\subsubsection{Probability Discount Rate Model Specification}

We now construct a likelihood function for our Task P time preference choices. Returning to our normalization used to derive Equation 6, we define the normalized present value for each lottery presented in a Task $\mathrm{P}$ choice. Recall that lottery $A$ provided payoff at future time $t$, and lottery $B$ provided payoff at future time $t+\tau$. The present value of lottery $A$ is

$$
N P V_{A}=\left(\frac{1}{1+\delta}\right)^{t} \times p_{A}
$$

and the present value of lottery $B$ is

$$
N P V_{B}=\left(\frac{1}{1+\delta}\right)^{t+\tau} \times p_{B}
$$

where $p_{i}$ is the probability of earning the larger payoff in lottery $i$. We use these normalized present value expressions to construct a probabilistic choice rule for the $\mathrm{P}$ Task decisions. ${ }^{14}$ We let $\operatorname{Pr}_{i}^{P}(A)$ be the probability of choosing outcome A over outcome B in choice i of Task $\mathrm{P}$, and express this as

$$
\operatorname{Pr}_{i}^{P}(A)=\frac{N P V_{A}^{1 / \xi}}{N P V_{A}^{1 / \xi}+N P V_{B}^{1 / \xi}}
$$

where $\xi$ is a noise parameter that relates the sensitivity of choice probabilities to payoffs. Note that $\xi \rightarrow 0$ implies the lottery with larger expected value is given full weight, while $\xi \rightarrow \infty$ implies purely random choice with each lottery receiving equal weight. The conditional log likelihood function for time preference decisions

\footnotetext{
${ }^{14}$ This is the same stochastic choice specification used by Holt and Laury (2002). See Harrison and Rutström (2008, Sections 2.2 and 2.3) for further discussion of stochastic error terms, and see Wilcox (2008) for a thorough discission of stochastic models under risk.
} 
is

$$
\ln L^{\mathrm{P}}(\delta, \xi ; y)=\sum_{i}\left(\left(\ln \left(\operatorname{Pr}_{i}^{P}(A) \mid y_{i}=A\right)+\left(\ln \left(1-\operatorname{Pr}_{i}^{P}(A) \mid y_{i}=B\right)\right)\right.\right.
$$

where $y_{i}=j$ denotes selection of lottery $j$ in observation $i$.

\subsubsection{Joint Estimation Model Specification}

Our specification for joint estimation of risk and time preferences generally follows from Andersen et al. (2008). First, we specify the likelihood function for choices made in the risk task to estimate the risk parameter, $r$. Each pairwise choice made in the risk task was between two lotteries, and each lottery had two possible outcomes. For each lottery $i$, we write outcome $j$ as $M_{i j}$ and we let the probability of this outcome be $p\left(M_{i j}\right)$. We express the expected utility of a given lottery as

$$
E U_{i}=\sum_{j=1,2} p\left(M_{i j}\right) \times U\left(\omega+M_{i j}\right)
$$

In order to specify a likelihood function for joint estimation, we must first assume a parametric form for utility. Note that this assumption is not required for the probability discounting likelihood function defined above in Equation 13. We assume the CRRA form for utility and that the risk coefficient $r$ does not vary over the time period under consideration. We now rewrite $E U_{i}$ as

$$
E U_{i}=\sum_{j=1,2} p\left(M_{i j}\right) \times \frac{\left(\omega+M_{i j}\right)^{1-r}}{1-r}
$$

We introduce probabilistic choice function $\operatorname{Pr}_{i}^{R}(A)$ as the probability of a subject choosing lottery $A$ instead of lottery $B$ in choice $i$ of task R, and define the probability as

$$
\operatorname{Pr}_{i}^{R}(A)=\frac{E U_{A}^{1 / \mu}}{E U_{A}^{1 / \mu}+E U_{B}^{1 / \mu}}
$$

where $\mu$ is the associated behavioral noise parameter. We now write the conditional log-likelihood function as

$$
\ln L^{\mathrm{R}}(r, \mu ; y, \omega)=\sum_{i}\left(\left(\ln \left(\operatorname{Pr}_{i}^{R}(A) \mid y_{i}=A\right)+\left(\ln \left(1-\operatorname{Pr}_{i}^{R}(A) \mid y_{i}=B\right)\right)\right.\right.
$$

where $y_{i}=j$ denotes selection of lottery $j$ in observation $i$.

Next, we construct a similar likelihood function for time preferences by using the D Task choices. Recall that each of these choices consisted of two options: option A provided monetary amount $M_{A}$ at time $t$, and option B paid $M_{B}$ at time $t+\tau$. By assuming CRRA as the form of the utility function as before, we can 
rewrite Equations 1 and 2 as

$$
P V_{A}=\left(\frac{1}{1+\delta}\right)^{t} \times \frac{\left(\omega+M_{A}\right)^{1-r}}{1-r}+\left(\frac{1}{1+\delta}\right)^{t+\tau} \times \frac{\omega^{1-r}}{1-r}
$$

and

$$
P V_{B}=\left(\frac{1}{1+\delta}\right)^{t} \times \frac{\omega^{1-r}}{1-r}+\left(\frac{1}{1+\delta}\right)^{t+\tau} \times \frac{\left(\omega+M_{B}\right)^{1-r}}{1-r}
$$

We now use these present values to construct another probabilistic choice rule - this time for the D task choices. We let $\operatorname{Pr}_{i}^{D}(A)$ be the probability of a subject choosing outcome $A$ instead of outcome $B$ in choice $i$ of task $\mathrm{D}$, and define this probability as

$$
\operatorname{Pr}_{i}^{D}(A)=\frac{P V_{A}^{1 / \nu}}{P V_{A}^{1 / \nu}+P V_{B}^{1 / \nu}}
$$

where $\nu$ is a noise parameter as before. We now write the conditional log-likelihood function for choices from the time discounting task $\mathrm{D}$ as

$$
\ln L^{\mathrm{D}}(\delta, r, \mu, \nu ; y, \omega)=\sum_{i}\left(\left(\ln \left(\operatorname{Pr}_{i}^{D}(A) \mid y_{i}=A\right)+\left(\ln \left(1-\operatorname{Pr}_{i}^{D}(A) \mid y_{i}=B\right)\right)\right.\right.
$$

where $y_{i}=j$ denotes selection of outcome $j$ in choice $i$.

By combining Equations 16 and 18, we can write the joint log likelihood as

$$
\ln L(\delta, r, \mu, \nu ; y, \omega)=\ln L^{\mathrm{R}}+\ln L^{\mathrm{D}} .
$$

The joint likelihood above allows for nonlinear preferences over wealth. We can impose the assumption of risk neutrality on our data by re-estimating the equation above with the constraint that the CRRA coefficient is equal to one. The results from the constrained estimation serve as our benchmark for gauging the sensitivity of our discount rates estimates to nonlinearity in the utility function.

\subsubsection{Maximum Likelihood Estimation Results}

We maximize the likelihood functions defined above with version 10 of the Stata statistical software application. ${ }^{15}$ Because each subject provided 20 responses for each of the three tasks, we allow for within-subject clustered standard errors. Table 7 presents our maximum-likelihood estimates. We estimate an aggregate annual discount rate of 12.2 percent with the probability discounting (Task P) specification. The 95 percent confidence interval bounds put the estimate between 4.6 percent and 19.7 percent. This is on the lower end of

\footnotetext{
${ }^{15}$ Both the data and estimation routines are available at http://www.excen.gsu.edu/swarthout/LMSV/
} 
Table 7: Estimates of risk and time preferences, assuming zero background consumption

\begin{tabular}{|c|c|c|c|c|c|}
\hline Parameter & Estimate & $\begin{array}{c}\text { Standard } \\
\text { Error }\end{array}$ & $p$-value & $\begin{array}{c}\text { Lower } 95 \% \\
\text { Confidence } \\
\text { Interval }\end{array}$ & $\begin{array}{c}\text { Upper } 95 \% \\
\text { Confidence } \\
\text { Interval }\end{array}$ \\
\hline \multicolumn{6}{|c|}{ Probability Discounting Estimation (Task P) } \\
\hline$\delta$ & 0.122 & 0.039 & 0.000 & 0.046 & 0.197 \\
\hline$\xi$ & 0.045 & 0.008 & 0.000 & 0.030 & 0.060 \\
\hline \multicolumn{6}{|c|}{ Joint Estimation Constrained to Risk Neutrality (Task D) } \\
\hline$\delta$ & 0.555 & 0.066 & 0.000 & 0.418 & 0.674 \\
\hline$\nu$ & 0.041 & 0.004 & 0.000 & 0.033 & 0.050 \\
\hline \multicolumn{6}{|c|}{ Joint estimation (Tasks $R$ and $D$ ) } \\
\hline$r$ & 0.702 & 0.069 & 0.000 & 0.567 & 0.838 \\
\hline$\delta$ & 0.141 & 0.038 & 0.000 & 0.066 & 0.215 \\
\hline$\mu$ & 0.132 & 0.026 & 0.000 & 0.081 & 0.183 \\
\hline$\nu$ & 0.012 & 0.003 & 0.000 & 0.006 & 0.019 \\
\hline
\end{tabular}

previous estimates, and we wish to know how much higher our estimate would be had we followed the earlier literature in assuming risk neutrality. To do this, we use the joint estimation likelihood function described above but constrain the CRRA coefficient to be equal to one. These estimates are shown in the middle of Table 7. The maximum likelihood point estimate under the assumption of risk linear preferences is 55.5 percent with a lower 95 percent confidence interval bound of 41.8 percent. Thus, we find that there is no overlap between the confidence intervals between the two estimation techniques. Failing to control for risk aversion drastically overstates the degree of impatience in our sample. Our lower estimates from the probability task are more plausible in theory and in comparison to naturally-occurring rates. Our estimate is also in line with the 10.1 percent found by Andersen et al. (2008) in their nationally representative sample of adult Danes using the joint estimation technique to account for curvature. Nonetheless, it is quite a surprise to find this degree of patience among US undergraduates. To see whether this unexpected result is an anomaly of the elicitation procedure, we turn to the within-subjects comparison of results from unconstrained joint estimation.

We begin by looking at the estimates of risk aversion in the jointly-estimated model. The risk coefficient is estimated to be 0.702 and the confidence interval does not include zero. This confirms the hypothesis that our subjects are risk averse. Given this evidence of curvature of the utility function, we expect that the unconstrained jointly-estimated discount rate will be significantly lower than the joint estimation constrained to risk neutrality. Indeed, the discount rate is found to be 14.1 percent when utility curvature in taken into account compared to 55.5 percent when utility is assumed to be linear. The discount rate we found in our $\mathrm{P}$ 
task is slightly lower; however, the confidence intervals for the two estimates have substantial overlap. The two estimates are also very similar in terms of precision.

The estimates of the behavioral error terms $\xi, \nu$, and $\mu$ in Table 7 exhibit an interesting pattern. Recall that estimates of zero indicate that no noise is present in the decision process. In all tasks and specifications, we find evidence of some noise: none of the confidence intervals include zero. We find the estimated amount of noise is highest in the risk aversion task and lowest in the dollar discounting task. Andersen et al. (2008) also find a larger estimate of noise for the risk aversion task than the discount rate task and hypothesize that the risk aversion tasks were cognitively harder. The estimated noise in our probability discounting task is intermediate suggesting a more difficult task than dollar discounting but still cognitively easier than the risk aversion task of Holt and Laury (2002).

\subsection{Sensitivity to Background Consumption}

The probability discounting estimates developed in this paper are independent of the level of background consumption. Alternative estimation techniques, including those of Andersen et al. (2008) and Andreoni and Sprenger (2012), require an estimate of background consumption in order to estimate and control for the curvature of the utility function. For the above estimates, we assumed that $\omega=0$, but we can easily vary this assumption to gauge the sensitivity of our estimates. Andersen et al. (2008) find that their estimated discount rates are not very sensitive to the assumed level of $\omega$, while Andreoni and Sprenger (2012) find estimated discount rates double when estimated daily consumption is varied between $\$ 3.52$ to $\$ 14.09$. We show in Figure 2 the range of estimated average discount rates as the level of background consumption is varied. ${ }^{16}$ We see that discount rates from joint estimation increase from a low of 14.2 percent that we report in Table 7 to a high of about 20 percent as the background consumption parameter is increased. The estimated discount rate from our P Task do not vary with the assumed level of back ground consumption and are closest to the joint estimation results when background consumption is assumed to be zero.

\subsection{Probability Weighting}

We now relax our prior assumption that the utility function is linear in probabilities. We assume the probability weighting function to have the form proposed by Tversky and Kahneman (1992), with

$$
w(p)=\frac{p^{\gamma}}{\left(p^{\gamma}+(1-p)^{\gamma}\right)^{1 / \gamma}}
$$

for $0<p<1, w(0)=0$, and $w(1)=1$.

\footnotetext{
${ }^{16}$ In comparing Andreoni and Sprenger (2012) to our results, note that in their model $\omega$ has the opposite sign to ours.
} 


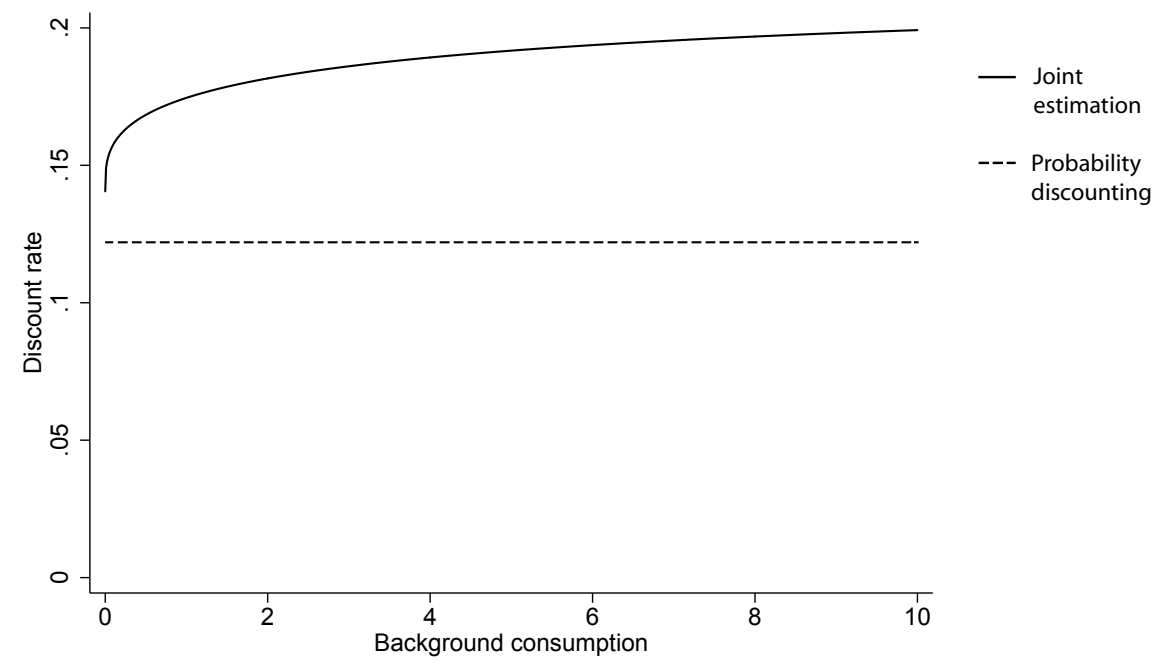

Figure 2: Estimated discount rates as daily background consumption varies between zero and ten dollars.

We use a joint estimation technique by combining subject responses from all three tasks to estimate the three unknown parameters: (i) the $\gamma$ of probability weighting function, (ii) the curvature parameter of the utility function $r$, and the discounting parameter $\delta$. Essentially this estimation approach boils down to using three equations to solve for three unknowns. The responses in each decision task depend on different combinations of two of the three unknown parameters, and it is only by combining all three tasks that we can identify all three parameters.

We proceed by modifying the log likelihood expressions associated with the two tasks involving uncertainty: the risk task and the binary payoff lottery discounting task. We first modify Equation $14^{\prime}$ by introducing the probability weighting function and denoting the higher paying outcome as $M_{i 1}$, to give us

$$
{ }_{w} E U_{i}=w\left(p\left(M_{i 1}\right)\right) \times \frac{\left(\omega+M_{i 1}\right)^{1-r}}{1-r}+\left(1-w\left(p\left(M_{i 1}\right)\right)\right) \times \frac{\left(\omega+M_{i 2}\right)^{1-r}}{1-r} .
$$

Thus, Equation 15 becomes

$$
{ }_{w} \operatorname{Pr}_{i}^{R}(A)=\frac{{ }_{w} E U_{A}^{1 / \mu}}{{ }_{w} E U_{A}^{1 / \mu}+{ }_{w} E U_{B}^{1 / \mu}} .
$$

And finally we have a modified log-likelihood function with probability weighting for the choices from the risk task, given as

$$
\ln _{w} L^{\mathrm{R}}(r, \mu, \gamma ; y, \omega)=\sum_{i}\left(\left(\ln \left({ }_{w} P r_{i}^{R}(A) \mid y_{i}=A\right)+\left(\ln \left(1-{ }_{w} P r_{i}^{R}(A) \mid y_{i}=B\right)\right)\right.\right.
$$

Similarly, we allow for probability weighting by constructing a modified log likelihood function for the P task 
choices. Following the derivation given in Equation $6^{\prime \prime}$, Equations 10 and 11 become

$$
{ }_{w} N P V_{A}=\left(\frac{1}{1+\delta}\right)^{t} \times w\left(p_{A}\right)
$$

and

$$
{ }_{w} N P V_{B}=\left(\frac{1}{1+\delta}\right)^{t+\tau} \times w\left(p_{B}\right) .
$$

This allows us to reexpress Equation 12 as

$$
{ }_{w} \operatorname{Pr}_{i}^{P}(A)=\frac{{ }_{w} N P V_{A}^{1 / \xi}}{{ }_{w} N P V_{A}^{1 / \xi}+{ }_{w} N P V_{B}^{1 / \xi}} .
$$

And now we have a log likelihood function for the P Task choices which allows for probability weighting, and is expressed as

$$
\ln _{w} L^{\mathrm{P}}(\delta, \xi, \gamma ; y)=\sum_{i}\left(\left(\ln \left({ }_{w} \operatorname{Pr}_{i}^{P}(A) \mid y_{i}=A\right)+\left(\ln \left(1-{ }_{w} \operatorname{Pr}_{i}^{P}(A) \mid y_{i}=B\right)\right)\right.\right.
$$

Because there is no uncertainty in the dollar discounting task, the likelihood contribution from the D Task data is unchanged by allowing for probability weighting. That is, $\ln _{w} L^{\mathrm{D}}=\ln L^{\mathrm{D}}$. Thus, we can express a joint log likelihood function for all three tasks as

$$
\ln _{w} L(\delta, r, \gamma, \mu, \nu, \xi ; y, \omega)=\ln _{w} L^{\mathrm{R}}+\ln _{w} L^{\mathrm{D}}+\ln _{w} L^{\mathrm{P}}
$$

Table 8: Estimates of Risk and Time Preferences with Probability Weighting

\begin{tabular}{cccccc}
\hline & & Standard & & $\begin{array}{c}\text { Lower 95\% } \\
\text { Confidence } \\
\text { Interval }\end{array}$ & $\begin{array}{c}\text { Upper 95\% } \\
\text { Confidence } \\
\text { Interval }\end{array}$ \\
\hline$r$ & 0.722 & 0.062 & 0.000 & 0.601 & 0.843 \\
$\delta$ & 0.130 & 0.031 & 0.000 & 0.068 & 0.191 \\
$\gamma$ & 0.996 & 0.098 & 0.000 & 0.804 & 1.187 \\
$\mu$ & 0.126 & 0.023 & 0.000 & 0.080 & 0.171 \\
$\nu$ & 0.011 & 0.003 & 0.000 & 0.006 & 0.017 \\
$\xi$ & 0.045 & 0.008 & 0.000 & 0.028 & 0.061 \\
\hline
\end{tabular}

The results of estimation allowing for probability weighting are shown in Table 8. The estimated discount rate of 13.0 percent is almost identical to that found when we assume probability weighting is absent. The CRRA coefficient is also similar to what we find when we use only the D Task and R Task data and assume no probability weighting. These results suggest that probability weighting has little impact in our experiment, 
and this is borne out by the fact that the confidence interval for $\gamma$ includes 1 . That is, we cannot reject the hypothesis that preferences are linear in probabilities. These results may be sensitive to our choice of probability weighting function, but we defer a more thorough exploration of parameterizations in the manner of Stott (2006) for a later date. Future work should also consider the link between an individual's probability weighting and hyperbolicity of time preferences as suggested by the findings of Epper et al. (2011).

\section{Sensitivity Test of Payment Delay}

A striking feature of these data is the large proportion of subjects who are willing to delay receiving payment at the lowest possible positive interest rate in the Probability Discount Rate Task. We do not observe this behavioral pattern in the Dollar Discount Rate Task in which discount rates are higher. The mean discount rate from the P-Task is 10.52-12.75 percent, but over one-third of all subjects reveal an individual discount rate below 1.01 percent. These subjects choose a 50.1 percent chance to earn $\$ 200$ in 12 weeks over a 50.0 percent chance to earn $\$ 200$ in 3 weeks.

We find it surprising that so many subjects respond so strongly to such a small increase in probability that they are willing to wait an additional nine weeks to receive payment. Because the joint-estimation technique yields only an aggregate curvature-free estimate of the discount rate, we cannot compare the distribution of individual discount rates obtained in the $\mathrm{P}$ Task to data from our jointly-estimated tasks. It is possible that this behavioral pattern may be the result of the specific parameters used for our probability discounting elicitation method in the first experiment. We conduct a second experiment to gauge sensitivity to parameter choices.

\subsection{Experimental Design and Procedures}

We implement four treatments in our second experiment (hereafter Experiment 2) to explore whether elicited discount rates are sensitive to the length of time participants must wait for payment. We manipulate both the horizon (i.e., the delay between the Sooner and Later payment dates) and the front-end delay (FED) (i.e., the waiting period before the payment date of the Sooner option). Table 9 defines the treatments. While our first experiment had a 3 week FED to hold constant the transaction costs and risks of receiving payment, our new experiment has FEDs of 2 weeks, 1 day, or 0 (i.e., payment is made at the end of the session before the subject leaves the laboratory). If preferences are hyperbolic (Ainslie, 1992) or quasi-hyperbolic (Laibson, 1997), then we expect to find that elicited discount rates will increase as the FED is reduced. Prior experimental research on the effects of the FED are mixed: Coller and Williams (1999) find that eliminating the FED significantly increases discount rates, while Anderson and Stafford (2009) find that reducing the 
FED to 1 day has no significant effects. We also vary the time horizon from 7 weeks to 1 week to investigate whether horizon influences the discount rate.

Table 9: Experiment 2 Treatments

\begin{tabular}{ccc}
\hline Treatment & Front-End Delay (days) & Horizon (days) \\
\hline Experiment 1 & 21 & 63 \\
\hline Baseline (Task A) & 14 & 49 \\
No FED (Task B) & 0 & 49 \\
Short FED (Task C) & 1 & 49 \\
Short Horizon (Task D) & 14 & 7 \\
\hline
\end{tabular}

Note that the baseline treatment uses a 2 week FED and a 7 week horizon, which is slightly shorter in both dimensions than our previous experiment. Comparing discount rates from Experiment 1 and the baseline for Experiment 2 will give us a gauge on whether the discount rate distribution is excessively sensitive to the specific parameters chosen in Experiment 1.

Table 10 shows the probabilities of payment for the Later option given on the decision sheet for each treatment and the implied discount rate ranges. We use the results from Experiment 1 to inform our choice of discount rate intervals in the current experiment. In Experiment 1, 60 percent of subjects switch to the later payment date by Row 8 , with switch points after this roughly evenly distributed across decision rows. Therefore, in Experiment 2 we keep the discount rate intervals the same as in Experiment 1 for the first 8 rows, but use wider intervals for the remaining decisions (and eliminate the very highest discount rate intervals where we see very little switching in Experiment 1).

We modify the procedures and instructions slightly for the new experiment. First, subjects make only P-Task elicitation decisions. Second, prior to subjects making any decisions, we go through two examples of how payoffs are determined with a sample P-Task decision sheet in the instructions. The parameters in the sample decision sheet differed from those used in the actual experiment. Third, we add a cover sheet to each task to draw attention to the time dimension for the choices in that task. One possible explanation for our Experiment 1 data is that some subjects may not have fully considered the time horizon difference and instead focused only on the probability of receiving payment. If this is so, then subjects would be more likely to switch to the Later option whenever it had the higher probability of payment. The cover sheet included the payment amount (which was fixed across all tasks) and the payment dates but did not include the probabilities. For example, the cover sheet for the baseline treatment stated:

Before Making Any Decisions in This Task, Please Note:

Your choice in this Task is between two options that offer a chance of being paid $\$ 100$ at different times this semester. 
Table 10: Experiment 2 choices and implied ranges of discount rates.

\begin{tabular}{cccc}
\hline & $\begin{array}{c}\text { Chance of receiving } \$ 100 \\
\text { from Later option(percent) }\end{array}$ & \\
\cline { 2 - 3 } & $\begin{array}{c}\text { Baseline, } \\
\text { NoFED, }\end{array}$ & $\begin{array}{c}\text { Range of discount rate } \\
\text { if switching in } \\
\text { this row (percent) }\end{array}$ \\
\cline { 2 - 3 } Row & ShortFED & ShortHorizon & $\delta \leq 0.00$ \\
2 & 50.00 & 50.00 & $0.00 \leq \delta \leq 1.01$ \\
3 & 50.07 & 50.01 & $1.01 \leq \delta \leq 2.02$ \\
4 & 50.13 & 50.02 & $2.02 \leq \delta \leq 4.08$ \\
5 & 50.27 & 50.04 & $4.08 \leq \delta \leq 6.18$ \\
6 & 50.40 & 50.06 & $6.18 \leq \delta \leq 8.33$ \\
7 & 50.54 & 50.08 & $8.33 \leq \delta \leq 10.52$ \\
8 & 50.68 & 50.10 & $10.52 \leq \delta \leq 12.75$ \\
9 & 50.81 & 50.12 & $12.75 \leq \delta \leq 17.35$ \\
0 & 51.09 & 50.15 & $17.35 \leq \delta \leq 22.13$ \\
11 & 51.71 & 50.19 & $22.13 \leq \delta \leq 28.39$ \\
12 & 52.05 & 50.24 & $28.39 \leq \delta \leq 34.97$ \\
13 & 52.76 & 50.29 & $34.97 \leq \delta \leq 49.15$ \\
14 & 55.29 & 50.72 & $49.15 \leq \delta \leq 111.54$ \\
\hline Note: & the chance of receiving $\$ 100$ & from the Sooner option is \\
always $50 \%$. & &
\end{tabular}

\section{Payment for Option A will be in 14 days (2 weeks) - on Tuesday, October 11 \\ Payment for Option B will be in 63 days (7 weeks) - on Tuesday, November 29}

If you have any questions, raise your hand and one of us will come to you.

This experiment was conducted in two sessions on Tuesday, September 27, 2011. The sessions were held on the same day so that all future dates were held constant across sessions. We purposefully chose to conduct the experiment on a Tuesday so that all future payment dates were either on a Tuesday or Wednesday, when most students are already on campus. We also ensured that none of the future payment dates conflicted with a holiday or final exams. A total of 75 undergraduate students participated.

In the new experiment, subjects participated in four decision-making tasks. Because they completed one additional task (relative to Experiment 1), we reduced the number of decisions subjects made from 20 to 14 in each of the four tasks. All subjects made decisions in all four tasks, but we randomly varied the order of tasks for each subject. After all four tasks were completed, subjects filled out a demographic questionnaire and then were paid privately their experiment earnings.

To determine experiment earnings, one of the four decision-making tasks was randomly chosen to count for payment. For this chosen decision-making task, a die-throw determined which one of the 14 decisions would count for payment. For this selected decision, the subject's choice of the Sooner or Later payment 


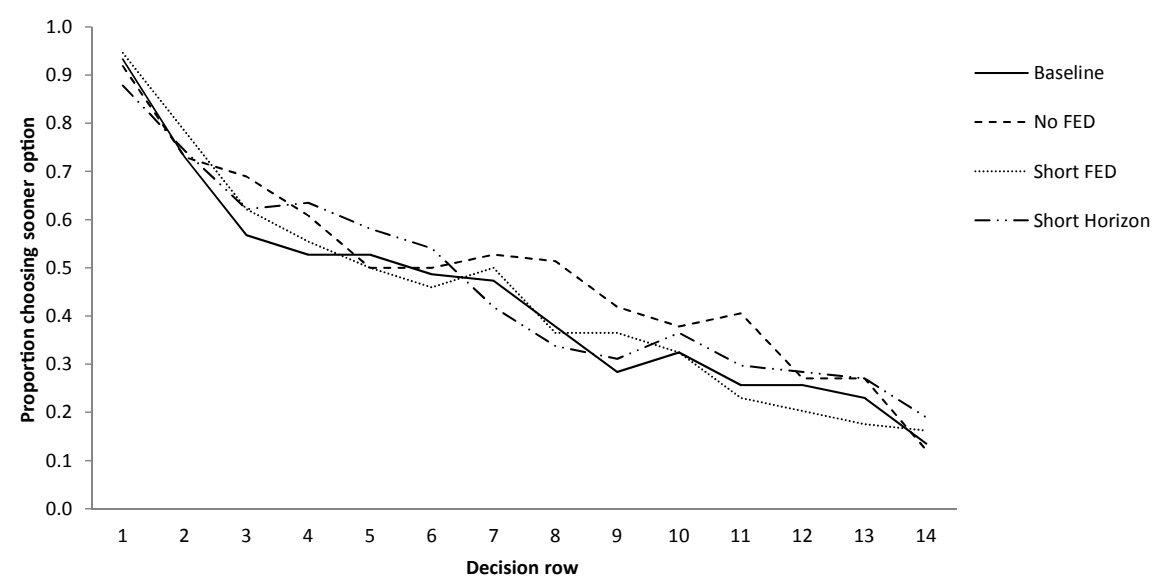

Figure 3: Proportion of subjects choosing the Sooner option (option A) in Experiment 2 by decision row and treatment.

determined the probability of earning $\$ 100$ (and on what date). A final die throw determined whether the subject earned $\$ 100$ or nothing.

In addition to these experiment earnings ( $\$ 100$ or nothing), each subject also received a $\$ 25$ participation payment ( $\$ 5$ for each of the four tasks plus $\$ 5$ for completing the demographic questionnaire). Thus, each subject earned either $\$ 25$ or $\$ 125$.

\subsection{Results}

Figure 3 displays the proportion of subjects selecting the Sooner payment in each of the 14 decisions for each treatment. Recall that the AEIR increases as the subject moves down the decision sheet so that a greater number of Sooner choices implies a higher discount rate. In all treatments, there is a sizeable drop in the fraction of subjects choosing the Sooner option between the first and second decisions, which corresponds to an increase in the AEIR from 0 percent to 1 percent. This is similar to the pattern we saw in Figure 1 for the P-Task data in the corresponding interest rate range. As the AEIR is raised further, we see that the portion selecting the Sooner option continues to drop but at a more gradual pace. In comparing across the treatments, the No FED treatment typically has a higher proportion of Sooner choices at any decision row relative to the Baseline while the other treatments are less obviously distinct. Wilcoxon Signed Rank tests comparing the distribution of the number of Sooner responses confirm this pattern. Table 11 reports these tests. We observe statistically significant present bias only for the No FED treatment. For the Short FED and Short Horizon treatments, we cannot reject the null that the distribution of the number of Sooner choices is the same relative to the Baseline treatment.

This pattern of behavior can also be seen in Table 12, which shows switching behavior and implied 
Table 11: Wilcoxon Signed Rank tests of equal distributions. All tests are two-tailed.

\begin{tabular}{ccccccccc}
\hline & \multicolumn{4}{c}{ All subjects } & & \multicolumn{3}{c}{ Excluding multiswitchers } \\
\cline { 2 - 3 } Test & $\mathrm{n}$ & $\mathrm{z}$ & prob $>|z|$ & & $\mathrm{n}$ & $\mathrm{z}$ & prob $>|z|$ \\
\hline Baseline = No FED & 75 & -2.019 & 0.0435 & & 53 & -1.749 & 0.0803 \\
Baseline = Short FED & 75 & -0.586 & 0.5579 & & 52 & -0.838 & 0.4019 \\
Baseline = Short Horizon $^{1}$ & 74 & -1.079 & 0.2805 & & 53 & -1.250 & 0.2112 \\
\hline
\end{tabular}

${ }^{1}$ We exclude one subject who circled both options on row 5 of the Short Horizon treatment.

discount ranges in each of our four new treatments. ${ }^{17}$ The overall pattern of behavior is quite similar to that observed with the parameters used in Experiment 1: the modal discount rate is between 0.00 and 1.01 percent, and the vast majority of subjects make choices consistent with a discount rate below 12.75 percent. We do see differences, however. In the Baseline treatment, just over 30 percent of all subjects exhibit a discount rate below 1.01 percent, which is lower than the 33.8 percent shown in Table 6 . When there is no front-end delay, this falls substantially: just 22.03 percent of subjects exhibit a discount rate below 1.01. Elicited discount rates fall between these extremes for our other two treatments, short FED (24.56 percent of subjects show a discount rate below 1.01 percent) and short horizon (27.58 percent of subjects with a discount rate below 1.01 percent). Overall, it appears that discount rates are more sensitive to the frontend-delay than the time-horizon between payment periods. We continue to investigate the effect of FED and horizon with a structural model in the next section.

\subsubsection{Structural Estimation}

We design the estimation procedure specifically to test for treatment effects. We construct binary indicator variables for each of the non-Baseline treatments ${ }^{18}$ and otherwise follow the model specification of Section 4.1.1. Estimating this model will provide us with a parameter estimate of $\delta^{B}$, the discount rate associated with baseline observations, as well as the additive change in the discount rate associated with each of the non-baseline treatments, as given by $\delta^{N F}, \delta^{S F}$, and $\delta^{S H}$.

Table 13 reports the maximum likelihood estimation of this model specification. We see that the discount rate associated with the Baseline treatment is 11.3 percent, which is very close to the 12.2 percent discount rate obtained from the prior experiment P-Task estimation. Further, the confidence intervals associated with both of these estimates are nearly identical. We view this similarity as a successful replication of the P-task results from the first experiment.

\footnotetext{
${ }^{17}$ As with Table 6 , subjects who switch more than once are excluded from this tabulation.

${ }^{18} \mathbf{d} \_$NF is equal to 1 if an observation is from the No FED treatment, 0 otherwise; $\mathbf{d} \_$SF is equal to 1 if an observation is from the Short FED treatment, 0 otherwise; d_SH is equal to 1 if an observation is from the Short Horizon treatment, 0 otherwise. We now express the discount rate as $\delta=\delta^{B}+\delta^{N F} \times \mathbf{d} \_\mathbf{N F}+\delta^{S F} \times \mathbf{d} \_\mathbf{S F}+\delta^{S H} \times \mathbf{d} \_\mathbf{S H}$.
} 
Table 12: Experiment 2 choices, implied discount rate ranges, and switching behavior by treatment.

\begin{tabular}{|c|c|c|c|c|c|}
\hline \multirow[b]{2}{*}{ Row } & \multirow{2}{*}{$\begin{array}{l}\text { Range of discount } \\
\text { rate if switching } \\
\text { in this row } \\
\text { (percent) }\end{array}$} & \multicolumn{4}{|c|}{$\begin{array}{l}\text { Proportion switching in } \\
\text { this row (percent) }\end{array}$} \\
\hline & & Baseline $^{1}$ & NoFED $^{2}$ & ShortFED ${ }^{3}$ & ShortHorizon $^{4}$ \\
\hline 1 & $\delta \leq 0.00$ & 3.57 & 1.69 & 3.51 & 5.17 \\
\hline 2 & $0.00 \leq \delta \leq 1.01$ & 26.79 & 20.34 & 21.05 & 22.41 \\
\hline 3 & $1.01 \leq \delta \leq 2.02$ & 10.71 & 10.17 & 12.28 & 3.45 \\
\hline 4 & $2.02 \leq \delta \leq 4.08$ & 3.57 & 10.17 & 7.02 & 6.90 \\
\hline 5 & $4.08 \leq \delta \leq 6.18$ & 1.79 & 3.39 & 1.75 & 3.45 \\
\hline 6 & $6.18 \leq \delta \leq 8.33$ & 5.36 & 3.39 & 5.26 & 5.17 \\
\hline 7 & $8.33 \leq \delta \leq 10.52$ & 3.57 & 1.69 & 3.51 & 13.79 \\
\hline 8 & $10.52 \leq \delta \leq 12.75$ & 5.36 & 0.00 & 7.02 & 6.90 \\
\hline 9 & $12.75 \leq \delta \leq 17.35$ & 10.71 & 8.47 & 8.77 & 1.72 \\
\hline 0 & $17.35 \leq \delta \leq 22.13$ & 1.79 & 3.39 & 0.00 & 0.00 \\
\hline 11 & $22.13 \leq \delta \leq 28.39$ & 3.57 & 0.00 & 5.26 & 5.17 \\
\hline 12 & $28.39 \leq \delta \leq 34.97$ & 1.79 & 10.17 & 7.02 & 0.00 \\
\hline 13 & $34.97 \leq \delta \leq 49.15$ & 5.36 & 3.39 & 1.75 & 3.45 \\
\hline 14 & $49.15 \leq \delta \leq 111.54$ & 7.14 & 10.17 & 5.26 & 8.62 \\
\hline \multicolumn{6}{|c|}{$\begin{array}{l}{ }^{1} \text { Including only the } 56 \text { subjects who did not multiswitch. Five subjects always chose } \\
\text { the Sooner option, implying a discount rate of at least } 111.54 \text { percent. } \\
2 \text { Including only the } 59 \text { subjects who did not multiswitch. Eight subjects always chose } \\
\text { the Sooner option, implying a discount rate of at least } 111.54 \text { percent. } \\
{ }^{3} \text { Including only the } 57 \text { subjects who did not multiswitch. Six subjects always chose } \\
\text { the Sooner option, implying a discount rate of at least } 111.54 \text { percent. } \\
{ }^{4} \text { Including only the } 58 \text { subjects who did not multiswitch. Eight subjects always chose } \\
\text { the Sooner option, implying a discount rate of at least } 111.54 \text { percent. }\end{array}$} \\
\hline
\end{tabular}

Table 13: Estimation of time preferences in Experiment 2 allowing for treatment effects

\begin{tabular}{cccccc}
\hline & Estimate & $\begin{array}{c}\text { Standard } \\
\text { Error }\end{array}$ & $p$-value & $\begin{array}{c}\text { Lower 95\% } \\
\text { Confidence } \\
\text { Interval }\end{array}$ & $\begin{array}{c}\text { Upper 95\% } \\
\text { Confidence } \\
\text { Interval }\end{array}$ \\
\hline$\delta^{B}$ & 0.113 & 0.035 & 0.001 & 0.044 & 0.183 \\
$\delta^{N F}$ & 1.574 & 0.322 & 0.000 & 0.943 & 2.205 \\
$\delta^{S F}$ & 1.049 & 0.197 & 0.000 & 0.663 & 1.435 \\
$\delta^{S H}$ & 0.000 & 0.001 & 0.852 & -0.002 & 0.002 \\
$\xi$ & 0.027 & 0.004 & 0.000 & 0.019 & 0.035 \\
\hline
\end{tabular}


We now examine treatment effects. The most extreme effect is the increased discount rate in the No FED treatment; having no delay for the sooner payment increases the estimated discount rate to 168.7 percent. Similarly, a one day FED results in an estimated discount rate of 116.2 percent. Both of these treatment effects are significant at any standard level of confidence. Because future payments have higher transaction costs and risks, we expect the discount rate to increase when the FED is eliminated (Coller and Williams, 1999). Considering only the no FED treatment, we cannot disentangle the effects of transaction costs from a "passion for the present." However, by comparing the no FED and one-day FED results, we infer that a "passion for the present" accounts for at least two-thirds of the observed discount rate increase in the No FED treatment. Finally, we estimate no change from the baseline discount rate in the Short Horizon treatment; the estimated effect associated with this treatment is less than 0.1 percent.

Much of the literature finding evidence in favor of hyperbolic over exponential discounting has relied on parametric assumptions about the utility function (Rohde, 2010). Our estimation results do not require such assumptions, and so provide new evidence against constant discounting, particularly when there is the chance at an immediate or one-day payment. However, if the soonest payment date is at least two weeks in the future, then we do not reject constant discounting in Experiment 2. Moreover, we also see that discount rates are in the same range across Experiment 1 and the Baseline treatment of Experiment 2. These results suggest that over this time range, the exponential model may be a reasonable local approximation of time preferences.

\section{Conclusion}

We develop a simple probability-based elicitation of time preferences and find a surprisingly low discount rate relative to the literature. The advantage of varying probabilities rather than prizes is that if expected utility is linear in probabilities, we can avoid the issues associated with estimating and correcting for the curvature of the utility function. Using the probability discounting elicitation method, we find average discounts rates of 12.2 percent in the first experiment and 11.3 percent in the second experiment when the front-end delay is at least two weeks. Because of the huge variation of discount rate estimates in the literature - even for those that address the curvature confound and, like ours, use real-valued rewards - we conduct a within-subjects comparison between our elicitation procedure and that of Andersen et al. (2008). We find very similar results with both methods, though this similarity depends on the parametric assumptions of the utility function required for joint estimation. Given that the two different methods elicit preferences in two different dimensions (probabilities versus monetary amounts), we are encouraged by these results. We observe low discount rates among a population hither-to-now thought to be (at least by the authors) 
excessively impatient. Given prevailing interest rates at the time the study was conducted, perhaps we should not be so surprised to find one-third of our participants were willing to save with us for the duration of the semester when offered as little as 1.02 percent.

We conduct a second experiment to explore the robustness of our findings to a reduction in front-end delay and time horizon of payment. We find that when the sooner payment takes place at the conclusion of the experimental session during which decisions are made (zero FED), estimated discount rates are significantly higher than in our baseline treatment with a two-week FED. However, even with no FED, 22 percent of subjects are willing to wait to receive payment at an AEIR of just 1.01 percent. Increasing the FED to one day also leads to a significant increase in the estimated discount rate relative to the baseline FED of two weeks. Both of these results indicate significant present-bias in our data. In contrast, changing the time horizon between payment dates from one week to seven weeks has no significant effect on the estimated discount rate.

A potential advantage of a single elicitation procedure, as compared with a dual elicitation procedure, is ease of implementation, which is a non-trivial consideration in field settings. In addition, the discount rate estimate from the P Task is independent of any errors in estimating the curvature of the utility function (as long as preferences are linear in probabilities). The same logic that shows the importance of correcting for the curvature of the utility function also shows that an error in estimating curvature will be propagated to the discount rate estimate. Overestimate the curvature and the discount rate will be biased downward. Underestimate, and the discount rate will be biased upward. Another vexing issue with estimating the curvature of the utility function is the need to estimate other parameters such as the level of background consumption. As long as background consumption is invariant over the time frame of the elicitation, we can safely avoid the need to estimate this parameter by use of the probability discounting procedure.

Moving forward with this research, more work needs to be done to consider non-expected utility frameworks. Our method does assume that preferences are linear in probabilities. Because of this, we test for evidence of probability weighting in our data. We do not find support for such weighting, given our subject pool and parameter values. In other populations and for other parameter values this may not be the case. We show in Section 2 that judicious choice of the parameter values may enable an experimenter with a good a priori sense of the form of probability weighting in her population to minimize it's impact. The alternative would be to administer multiple probability discounting tasks and then estimate both the probability weighting function as well as the discount rate. Note that there is still an advantage to using probability discounting tasks rather than monetary discounting tasks, in that at least we can avoid specifying and estimating the value function. 


\section{Acknowledgements}

We thank seminar participants at Emory University, University of South Carolina, and Xiamen University, as well as conference participants at the 2009 Economic Science Association North American Regional Meeting, the 2010 Foundations and Applications of Utility, Risk and Decision Theory International Conference, the 2010 Southern Economic Association Annual Meeting, and the 2012 International Meeting on Experimental and Behavioural Economics. We especially want to acknowledge and thank Glenn Harrison for his timely and detailed comments on earlier drafts. All errors remain our own.

\section{References}

Ainslie, G. (1992). Picoeconomics: The Strategic Interaction of Successive Motivational States within the Person. Cambridge University Press.

Andersen, S., Harrison, G. W., Lau, M. I., and Rutström, E. E. (2008). Eliciting risk and time preferences. Econometrica, 76, 583-618.

Anderson, L. R., and Stafford, S. L. (2009). Individual decision-making experiments with risk and intertemporal choice. Journal of Risk and Uncertainty, 38, 51-72.

Andreoni, J., and Sprenger, C. (2012). Estimating time preferences from convex budgets. American Economic Review, forthcoming.

Binswanger, H. P. (1980). Attitudes toward risk: Experimental measurement in rural india. American Journal of Agricultural Economics, 62, 395-407.

Coble, K. H., and Lusk, J. L. (2010). At the nexus of risk and time preferences: An experimental investigation. Journal of Risk and Uncertainty, 41, 67-79.

Coller, M., and Williams, M. B. (1999). Eliciting individual discount rates. Experimental Economics, 2, $107-127$.

Epper, T., Fehr-Duda, H., and Bruhin, A. (2011). Viewing the future through a warped lens: Why uncertainty generates hyperbolic discounting. Journal of Risk and Uncertainty, 43, 169-203.

Frederick, S., Loewenstein, G., and O'donoghue, T. (2002). Time discounting and time preference: A critical review. Journal of Economic Literature, 40, 351-401.

Fudenberg, D., and Levine, D. K. (2006). A dual-self model of impulse control. The American Economic Review, 96, 1449-1476. 
Harrison, G. W., and Rutström, E. (2008). Risk aversion in the laboratory. In J. C. Cox, and G. W. Harrison (Eds.), Risk Aversion in Experiments, volume 12 of Research in Experimental Economics, Emerald Group Publishing Limited, 41-196.

Harvey, C. M. (1986). Value functions for infinite-period planning. Management Science, 32, 1123-1139.

Hey, J. D., and Orme, C. (1994). Investigating generalizations of expected utility theory using experimental data. Econometrica, 62, 1291-1326.

Holt, C. A., and Laury, S. K. (2002). Risk aversion and incentive effects. The American Economic Review, 92, 1644-1655.

Keller, L. R., and Strazzera, E. (2002). Examining predictive accuracy among discounting models. Journal of Risk and Uncertainty, 24, 143-160.

Kreps, D. M., and Porteus, E. L. (1978). Temporal resolution of uncertainty and dynamic choice theory. Econometrica, 46, 185-200.

Laibson, D. (1997). Golden eggs and hyperbolic discounting. Quarterly Journal of Economics, 112, 443-477.

Morgan, E. (2009). The Heir and the Spare: Impact of Birth Order on Risk Attitudes, Discount Rates, and Behaviors. Ph.D. thesis, University of South Carolina.

Noor, J. (2009). Hyperbolic discounting and the standard model: Eliciting discount functions. Journal of Economic Theory, 144, 2077-2083.

Prelec, D. (1998). The probability weighting function. Econometrica, 66, 497-527.

Rohde, K. I. (2010). The hyperbolic factor: A measure of time inconsistency. Journal of Risk and Uncertainty, 41, 125-140.

Roth, A. E., and Malouf, M. W. K. (1979). Game-theoretic models and the role of information in bargaining. Psychological Review, 86, 574-594.

Stott, H. P. (2006). Cumulative prospect theorys functional menagerie. Journal of Risk and Uncertainty, 32, 101-130.

Takeuchi, K. (2011). Non-parametric test of time consistency: Present bias and future bias. Games and Economic Behavior, 71, 456-478.

Tversky, A., and Kahneman, D. (1992). Advances in prospect theory: Cumulative representation of uncertainty. Journal of Risk and Uncertainty, 5, 297-323. 
Wilcox, N. T. (2008). Stochastic models for binary discrete choice under risk: A critical primer and econometric comparison. In J. C. Cox, and G. W. Harrison (Eds.), Risk Aversion in Experiments, volume 12 of Research in Experimental Economics, Emerald Group Publishing Limited, 197-292. 


\section{A Instructions and Decision Sheets}

\section{Introductory Instructions}

You are now participating in a decision-making experiment. Based on your decisions in this experiment, you can earn money that will be paid to you in cash. It is important that you understand all instructions before making your choices in this experiment.

Please turn off your cell phone, laptop computer, or any other device you may have brought with you. Please do not talk with others seated in the room for the duration of the experiment. If at any point you have a question, please raise your hand and we will address it as soon as possible.

The experiment consists of three decision-making tasks. You have earned $\$ 5$ for arriving for the experiment on time, and you will be paid another $\$ 5$ for each of the three tasks that you complete. So, if you complete all three decision-making tasks you will earn $\$ 20$ for participating in today's experiment.

In addition to your participation payment, you may earn considerably more from each task. Each of the decision tasks and the potential earnings from these tasks will be explained in detail as we proceed through the instructions. Your earnings from each of the three tasks will be calculated at the end of todays session after all three tasks are completed.

However, it is important that you know that you will not receive any earnings, other than your participation payments, unless you complete all three decision-making tasks. For example, if you leave right now you will be paid $\$ 5$ for coming to todays experiment. On the other hand if you leave after completing two of the three tasks today, you will receive $\$ 15$ but you will not be eligible to receive any other payments from todays experiment. If you complete all three tasks, you will receive your $\$ 20$ participation payment and be eligible to receive additional earnings based on your decisions in the three tasks.

Are there any questions so far?

\section{Task D Instructions}

Each person in this room has the chance to earn a large sum of money from this part of the experiment. The amount of money you earn in this part of the experiment will depend both on your choices and also on chance. We will first explain to you the choices that you will be making, and then how your earnings are determined.

\section{YOUR CHOICES}

In this part of the experiment, you will be asked to make a series of choices between Option A and Option B. 
Please look at the Decision Table. Each Decision row gives you a choice between Option A and Option B. As an example, look at the row for Decision 4. Your choice here is between Option A, which pays $\$ 200$ in three weeks, and Option B, which pays $\$ 201.39$ in 12 weeks.

Looking down the rows of the Decision Table you can see that you have 20 Decisions to make. In each of these Decisions, Option A represents a chance to earn $\$ 200$ in three weeks. With Option B, the amount of money paid in 12 weeks starts at $\$ 200$ in Decision 1 , and increases as you move down the rows in the Decision Table. For example, in Decision 13 Option A pays $\$ 200$ in 3 weeks and Option B pays $\$ 207.92$ in 12 weeks.

In the Decision Table there are two columns labeled "Annual Interest Rate" and "Annual Effective Interest Rate". To explain these terms, let us once again consider Decision 13:

Option A pays $\$ 200.00$ three weeks from today. Option B pays $\$ 207.9212$ weeks from today. In this example, if you choose option B you will earn an annual interest rate of $22.50 \%$ on the $\$ 200$ you will receive 12 weeks from today. The interest accrues starting 3 weeks from today, and is compounded daily, resulting in an annual effective interest rate of $25.22 \%$. The annual effective interest rate is the rate earned on the initial balance ( $\$ 200$ in this example) plus interest earned on all interest accumulated in the preceding compounding periods (daily, starting 3 weeks from now until 12 weeks from now).

You will make twenty choices. For each Decision row, you will have to choose between Option A and Option B. You may choose A for some Decision rows and B for other rows, and you may change your choice and make them in any order. So now please look at the boxes on the right side of the record sheet. You will have to circle your choice of A or B for each of the twenty Decisions.

Even though you will make twenty Decisions, only one of these will end up possibly affecting your earnings, but you will not know in advance which Decision will be used. Each Decision has an equal chance of being used for payment.

\section{HOW YOU WILL YOU BE PAID}

For each Decision row, choose whether you prefer A or B for that row. After you have made all 20 Decisions, we will throw a black 20-sided die. You can see this die on the lab monitors. The number that is thrown on the 20-sided die will determine which one of your 20 Decisions will count for payment. For example, if we throw a 12, we will look at Decision Row 12 to see if you chose Option A or Option B. We will not look at any of your other Decisions when we determine your earnings for this part of the experiment.

After this, we will throw a Black 10-sided die for the final payment phase. If the outcome is between 1 and 9, then none of your choices in this part of the experiment will count for payment. If the outcome is a 0, then your choice in the Decision chosen for payment will determine your earnings as described above.

Note that we will roll the dice individually for each person, and so each person is equally likely to receive 
payment in the final payment phase of the experiment. More than one person may be selected for payment, and each person selected will be paid the amount determined by their choices and die rolls as described above.

If you earn money in this task, we will give you a certificate for the payment you earn, redeemable in cash here in the Andrew Young School Building in three weeks or 12 weeks, depending on the option you choose. If you do earn this money, then at the end of the experiment we will give you more detailed instructions for redeeming your certificate and the location in this building where you will go to redeem your certificate.

\section{SUMMARY}

1. You will choose Option A or Option B for each of the 20 rows of the Decision Table.

2. We will throw a Black 20-sided die to determine which ONE of these Decisions will count. We will look at your choice in this Decision only.

3. Finally, we will throw a 10-sided die to determine whether or not this outcome will be paid. If we throw a 1-9 then you will not be paid for your Decision. If we throw a 0 , then you will receive payment according to whether you choose Option A or Option B. If the outcome is for you to receive money, then you will receive a certificate for payment that may be redeemed in three- or 12-weeks (depending on whether you chose Option A or Option B).

We will next go through a simple demonstration of this task before you make your choices. This demonstration is to help you better understand the task and will not count for money. Please listen and watch the demonstration before making your own choices.

If you have any questions, please raise your hand and one of us will come to your desk to answer it. 
Task D Decision Sheet (originally printed on legal paper)

Task D Decision Table

\begin{tabular}{|c|c|c|c|c|c|c|}
\hline Decision & $\begin{array}{c}\text { Option A } \\
\begin{array}{c}\text { (receive amount below in } \\
\text { three weeks) }\end{array}\end{array}$ & $\begin{array}{c}\text { Option B } \\
\begin{array}{c}\text { (receive amount below in } \\
\text { twelve weeks) }\end{array}\end{array}$ & $\begin{array}{c}\text { Annual } \\
\text { Interest } \\
\text { Rate }\end{array}$ & $\begin{array}{c}\text { Annual } \\
\text { Effective } \\
\text { Interest Rate }\end{array}$ & & \\
\hline 1 & $\$ 200$ & $\$ 200$ & $0 \%$ & $0 \%$ & A & B \\
\hline 2 & $\$ 200$ & $\$ 200.35$ & $1 \%$ & $1.01 \%$ & A & B \\
\hline 3 & $\$ 200$ & $\$ 200.69$ & $2 \%$ & $2.02 \%$ & $\mathrm{~A}$ & B \\
\hline 4 & $\$ 200$ & $\$ 201.39$ & $4 \%$ & $4.08 \%$ & A & B \\
\hline 5 & $\$ 200$ & $\$ 202.08$ & $6 \%$ & $6.18 \%$ & A & B \\
\hline 6 & $\$ 200$ & $\$ 202.78$ & $8 \%$ & $8.33 \%$ & A & B \\
\hline 7 & $\$ 200$ & $\$ 203.48$ & $10 \%$ & $10.52 \%$ & A & B \\
\hline 8 & $\$ 200$ & $\$ 204.18$ & $12 \%$ & $12.75 \%$ & A & B \\
\hline 9 & $\$ 200$ & $\$ 204.89$ & $14 \%$ & $15.02 \%$ & A & B \\
\hline 10 & $\$ 200$ & $\$ 205.60$ & $16 \%$ & $17.35 \%$ & A & B \\
\hline 11 & $\$ 200$ & $\$ 206.31$ & $18 \%$ & $19.72 \%$ & A & B \\
\hline 12 & $\$ 200$ & $\$ 207.02$ & $20 \%$ & $22.13 \%$ & A & B \\
\hline 13 & $\$ 200$ & $\$ 207.92$ & $22.5 \%$ & $25.22 \%$ & A & B \\
\hline 14 & $\$ 200$ & $\$ 208.82$ & $25 \%$ & $28.39 \%$ & A & B \\
\hline 15 & $\$ 200$ & $\$ 210.62$ & $30 \%$ & $34.97 \%$ & A & B \\
\hline 16 & $\$ 200$ & $\$ 214.29$ & $40 \%$ & $49.15 \%$ & A & B \\
\hline 17 & $\$ 200$ & $\$ 218.01$ & $50 \%$ & $64.82 \%$ & A & B \\
\hline 18 & $\$ 200$ & $\$ 227.61$ & $75 \%$ & $111.54 \%$ & A & B \\
\hline 19 & $\$ 200$ & $\$ 237.62$ & $100 \%$ & $171.46 \%$ & A & B \\
\hline 20 & $\$ 200$ & $\$ 258.96$ & $150 \%$ & $346.79 \%$ & A & B \\
\hline \multirow[t]{2}{*}{ ID $\mathrm{Nu}$} & $\begin{array}{l}\text { Decision } \\
\text { Row Roll }\end{array}$ & $\begin{array}{l}\text { Selection for } \\
\text { Payment Roll }\end{array}$ & & & & \\
\hline & Black-20 & $\begin{array}{l}\text { Black-10 } \\
(0=\text { pay })\end{array}$ & & & & \\
\hline
\end{tabular}




\section{Task P Instructions}

Each person in this room has the chance to earn a large sum of money from this part of the experiment. The amount of money you earn in this part of the experiment will depend both on your choices and also on chance. We will first explain to you the choices that you will be making, and then how your earnings are determined.

\section{YOUR CHOICES}

In this part of the experiment, you will be asked to make a series of choices between Option A and Option B. On the lab monitors, you can see three 10-sided die: a red die, a white die, and a blue die.

Your earnings in this part of the experiment depend, in part, on the outcome from rolling these three die. We will throw the dice, and then record the outcomes as a three digit number:

\section{$\underline{\text { RedDie\# WhiteDie\# } \quad \text { BlueDie\# }}$}

For example, if we threw a "6" on the Red Die, a "4" on the White Die, and a "0" on the Blue Die, the number recorded would be 640 . On the other hand, if we threw a "0" on the Red Die, "6" on the White Die and a " 4 " on the Blue Die, the number recorded would be 064. Notice that there are one thousand possible outcomes of the drawing. They can be listed as:

$$
\{001,002,003,004, \ldots, 996,997,998,999,000\}
$$

Each of these numbers has a 1-in-1000 chance of being thrown (if three zeros are thrown, this will represent an outcome of 1000).

Please look at the Decision Table. Each Decision row gives you a choice between Option A and Option B. As an example, look at the row for Decision 2. Option A pays $\$ 200$ in three weeks if the number thrown on the die is between 001 to 500 . Thus, there are 500-in-1000 chances of receiving $\$ 200$ if you choose Option A. This represents a $50 \%$ chance of winning. Now look at Option B for Decision 2. Option B pays $\$ 200$ in 12 weeks if the number thrown on the die is between 001 to 501 . There are 501-in-1000 chances (50.1\%) that the number drawn will be in this range. As you move down the table, Option A is always the same, but with Option B the chances of winning increase.

Looking down the rows of the Decision Table you can see that you have 20 Decisions to make. In each of these Decisions, Option A represents a chance to earn $\$ 200$ in three weeks if the number thrown on the die is between 001 and 500. In each of these Decisions, Option B represents a chance to earn $\$ 200$ in 12 weeks, with the chance of earning this money increasing as you move down the rows of the table. For example, 
in Decision 16, there is a 500-in-1000 chance of earning $\$ 200$ in 3 weeks if you choose Option A and a 536-in-1000 chance of earning $\$ 200$ in 12 weeks if you choose Option B.

You will make twenty choices. For each Decision row, you will have to choose between Option A and Option B. You may choose A for some Decision rows and B for other rows, and you may change your choice and make them in any order. So now please look at the boxes on the right side of the record sheet. You will have to circle your choice of A or B for each of the twenty Decisions.

Even though you will make twenty Decisions, only one of these will end up possibly affecting your earnings, but you will not know in advance which Decision will be used. Each Decision has an equal chance of being used for payment.

\section{HOW YOU WILL YOU BE PAID}

For each Decision row, choose whether you prefer A or B for that row. After you have made all 20 Decisions, we will throw a black 20-sided die. You can see this die on the lab monitors. The number that is thrown on the 20-sided die will determine which one of your 20 Decisions will count for payment. For example, if we throw a 12, we will look at Decision Row 12 to see if you chose Option A or Option B. We will not look at any of your other Decisions when we determine your earnings for this part of the experiment.

Next, we will throw the three colored 10-sided dice to determine whether the monetary outcome is $\$ 200$, as we described above. Continuing with the example for Decision 12, the table below illustrates the outcomes that would occur depending on the 3-digit die throw and whether you chose Option A or Option B.

\begin{tabular}{ccc}
\hline Die Throw & $\begin{array}{c}\text { Outcome If You } \\
\text { Choose Option A }\end{array}$ & $\begin{array}{c}\text { Outcome If You } \\
\text { Choose Option B }\end{array}$ \\
\hline $001-500$ & $\$ 200$ in 3 weeks & $\$ 200$ in 12 weeks \\
$501-518$ & $\$ 0$ & $\$ 200$ in 12 weeks \\
$519-000$ & $\$ 0$ & $\$ 0$ \\
\hline
\end{tabular}

Suppose instead that when we threw the 20-sided die we had determined that Decision 3 was the one that counts for payment. In this case, the table below illustrates the outcomes that would occur depending on the 3-digit die throw and whether you chose Option A or Option B.

\begin{tabular}{ccc}
\hline Die Throw & $\begin{array}{c}\text { Outcome If You } \\
\text { Choose Option A }\end{array}$ & $\begin{array}{c}\text { Outcome If You } \\
\text { Choose Option B }\end{array}$ \\
\hline $001-500$ & $\$ 200$ in 3 weeks & $\$ 200$ in 12 weeks \\
$501-502$ & $\$ 0$ & $\$ 200$ in 12 weeks \\
$503-000$ & $\$ 0$ & $\$ 0$ \\
\hline
\end{tabular}

After this, we will throw a Black 10-sided die for the final payment phase. If the outcome is between 2 and 9 , then none of your choices in this part of the experiment will count for payment. If the outcome is a 0 or 1 , then your choices and the earlier rolls will determine your earnings as described above. 
Note that we will roll the dice individually for each person, and so each person is equally likely to receive payment in the final payment phase of the experiment. More than one person may be selected for payment, and each person selected will be paid the amount determined by their choices and die rolls as described above.

If you earn $\$ 200$ in this task, we will give you a certificate for $\$ 200$ redeemable in cash here in the Andrew Young School Building in three weeks or 12 weeks, depending on the option you choose. If you do earn this money, then at the end of the experiment we will give you more detailed instructions for redeeming your certificate and the location in this building where you will go to redeem your certificate.

\section{SUMMARY}

1. You will choose Option A or Option B for each of the 20 rows of the Decision Table.

2. We will throw a Black 20-sided die to determine which ONE of these Decisions will count.

3. We will look at the choice you made in this Decision, and then throw the three 10-sided dice (one red, one blue, and one white).

4. We will look at the three-digit-number that comes from the dice roll and also at your choice for this one Decision to determine the monetary outcome: receive $\$ 0$, receive $\$ 200$ in three weeks, or receive $\$ 200$ in 12 weeks.

5. Finally, we will throw a 10-sided die to determine whether or not this outcome will be paid. If we throw a 2-9 then you will not be paid for your Decision. If we throw a 0 or 1 , then you will receive payment according to the outcome in step \#4. If the outcome is for you to receive $\$ 200$, then you will receive a certificate for $\$ 200$ that may be redeemed in three- or 12 -weeks (depending on whether you chose Option A or Option B).

We will next go through a simple demonstration of this task before you make your choices. This demonstration is to help you better understand the task and will not count for money. Please listen and watch the demonstration before making your own choices.

If you have any questions, please raise your hand and one of us will come to your desk to answer it. 


\section{Task P Decision Sheet (originally printed on legal paper)}

\section{Task P Decision Table}

\begin{tabular}{|c|c|c|c|c|c|c|}
\hline \multirow[t]{2}{*}{ Decision } & \multicolumn{2}{|l|}{$\begin{array}{c}\text { Option A } \\
\text { (Pays \$200 in three weeks) } \\
\end{array}$} & \multicolumn{2}{|l|}{$\begin{array}{c}\text { Option B } \\
\text { (Pays \$200 in twelve weeks) }\end{array}$} & \multicolumn{2}{|c|}{$\begin{array}{c}\text { Preferred } \\
\text { Option } \\
\text { (Circle } \\
\text { A or B) }\end{array}$} \\
\hline & Winning Numbers for Option A & $\begin{array}{c}\text { Chances of } \\
\text { winning }\end{array}$ & Winning Numbers for Option B & $\begin{array}{l}\text { Chances of } \\
\text { winning }\end{array}$ & & \\
\hline 1 & $\begin{array}{l}\text { You receive } \$ 200 \text { in three weeks if the } \\
\text { \# rolled is between } \underline{0} \underline{0} 1 \text { and } \underline{5} \underline{0} \underline{0} .\end{array}$ & $50.0 \%$ & $\begin{array}{l}\text { You receive } \$ 200 \text { in twelve weeks if the } \\
\text { \# rolled is between } \underline{0} \underline{0} 1 \text { and } \underline{5} \underline{0} \underline{0} .\end{array}$ & $50.0 \%$ & A & B \\
\hline 2 & $\begin{array}{l}\text { You receive } \$ 200 \text { in three weeks if the } \\
\text { \# rolled is between } \underline{0} \underline{0} 1 \text { and } \underline{5} \underline{0} \underline{0} \text {. }\end{array}$ & $50.0 \%$ & $\begin{array}{l}\text { You receive } \$ 200 \text { in twelve weeks if the } \\
\text { \# rolled is between } \underline{0} \underline{0} \underline{1} \text { and } \underline{5} \underline{0} \underline{1} \text {. }\end{array}$ & $50.1 \%$ & $\mathrm{~A}$ & B \\
\hline 3 & $\begin{array}{l}\text { You receive } \$ 200 \text { in three weeks if the } \\
\text { \# rolled is between } \underline{0} \underline{0} \underline{1} \text { and } \underline{5} \underline{0} \underline{0} \text {. }\end{array}$ & $50.0 \%$ & $\begin{array}{l}\text { You receive } \$ 200 \text { in twelve weeks if the } \\
\text { \# rolled is between } \underline{0} \underline{0} \underline{1} \text { and } \underline{5} \underline{0} \underline{2} \text {. }\end{array}$ & $50.2 \%$ & A & B \\
\hline 4 & $\begin{array}{l}\text { You receive } \$ 200 \text { in three weeks if the } \\
\text { \# rolled is between } \underline{0} \underline{0} \underline{1} \text { and } \underline{5} \underline{0} \underline{0} .\end{array}$ & $50.0 \%$ & $\begin{array}{l}\text { You receive } \$ 200 \text { in twelve weeks if the } \\
\text { \# rolled is between } \underline{0} \underline{0} \underline{1} \text { and } \underline{5} \underline{0} \underline{4} \text {. }\end{array}$ & $50.4 \%$ & A & B \\
\hline 5 & $\begin{array}{l}\text { You receive } \$ 200 \text { in three weeks if the } \\
\text { \# rolled is between } \underline{0} \underline{0} \underline{1} \text { and } \underline{5} \underline{0} \underline{0} .\end{array}$ & $50.0 \%$ & $\begin{array}{l}\text { You receive } \$ 200 \text { in twelve weeks if the } \\
\text { \# rolled is between } \underline{0} \underline{0} \underline{1} \text { and } \underline{5} \underline{0} \underline{5} \text {. }\end{array}$ & $50.5 \%$ & $\mathrm{~A}$ & B \\
\hline 6 & $\begin{array}{l}\text { You receive } \$ 200 \text { in three weeks if the } \\
\text { \# rolled is between } \underline{0} \underline{0} \underline{1} \text { and } \underline{5} \underline{0} \underline{0} .\end{array}$ & $50.0 \%$ & $\begin{array}{l}\text { You receive } \$ 200 \text { in twelve weeks if the } \\
\text { \# rolled is between } \underline{0} \underline{0} \underline{1} \text { and } \underline{5} \underline{0} \underline{7} \text {. }\end{array}$ & $50.7 \%$ & $\mathrm{~A}$ & B \\
\hline 7 & $\begin{array}{l}\text { You receive } \$ 200 \text { in three weeks if the } \\
\text { \# rolled is between } \underline{0} \underline{0} \underline{1} \text { and } \underline{5} \underline{0} \underline{0} \text {. }\end{array}$ & $50.0 \%$ & $\begin{array}{l}\text { You receive } \$ 200 \text { in twelve weeks if the } \\
\text { \# rolled is between } \underline{0} \underline{0} \underline{1} \text { and } \underline{5} \underline{0} \underline{9} \text {. }\end{array}$ & $50.9 \%$ & A & B \\
\hline 8 & $\begin{array}{l}\text { You receive } \$ 200 \text { in three weeks if the } \\
\text { \# rolled is between } \underline{0} \underline{0} \underline{1} \text { and } \underline{5} \underline{0} \underline{0} .\end{array}$ & $50.0 \%$ & $\begin{array}{l}\text { You receive } \$ 200 \text { in twelve weeks if the } \\
\text { \# rolled is between } \underline{0} \underline{0} \underline{1} \text { and } \underline{5} \underline{1} \underline{1} \text {. }\end{array}$ & $51.1 \%$ & A & B \\
\hline 9 & $\begin{array}{l}\text { You receive } \$ 200 \text { in three weeks if the } \\
\text { \# rolled is between } \underline{0} \underline{0} \underline{1} \text { and } \underline{5} \underline{0} \underline{0} .\end{array}$ & $50.0 \%$ & $\begin{array}{l}\text { You receive } \$ 200 \text { in twelve weeks if the } \\
\text { \# rolled is between } \underline{0} \underline{0} \underline{1} \text { and } \underline{5} \underline{2} .\end{array}$ & $51.2 \%$ & $\mathrm{~A}$ & B \\
\hline 10 & $\begin{array}{l}\text { You receive } \$ 200 \text { in three weeks if the } \\
\text { \# rolled is between } \underline{0} \underline{0} \underline{1} \text { and } \underline{5} \underline{0} \underline{0} .\end{array}$ & $50.0 \%$ & $\begin{array}{l}\text { You receive } \$ 200 \text { in twelve weeks if the } \\
\text { \# rolled is between } \underline{0} \underline{0} \underline{1} \text { and } \underline{5} \underline{1} \underline{4} \text {. }\end{array}$ & $51.4 \%$ & A & B \\
\hline 11 & $\begin{array}{l}\text { You receive } \$ 200 \text { in three weeks if the } \\
\text { \# rolled is between } \underline{0} \underline{0} \underline{1} \text { and } \underline{5} \underline{0} \underline{0} \text {. }\end{array}$ & $50.0 \%$ & $\begin{array}{l}\text { You receive } \$ 200 \text { in twelve weeks if the } \\
\text { \# rolled is between } \underline{0} \underline{0} \underline{1} \text { and } \underline{5} \underline{1} \underline{6} \text {. }\end{array}$ & $51.6 \%$ & A & B \\
\hline 12 & $\begin{array}{l}\text { You receive } \$ 200 \text { in three weeks if the } \\
\text { \# rolled is between } \underline{0} \underline{0} \underline{1} \text { and } \underline{5} \underline{0} \underline{0} .\end{array}$ & $50.0 \%$ & $\begin{array}{l}\text { You receive } \$ 200 \text { in twelve weeks if the } \\
\text { \# rolled is between } \underline{0} \underline{0} \underline{1} \text { and } \underline{5} \underline{1} \underline{8} \text {. }\end{array}$ & $51.8 \%$ & A & B \\
\hline 13 & $\begin{array}{l}\text { You receive } \$ 200 \text { in three weeks if the } \\
\text { \# rolled is between } \underline{0} \underline{0} \underline{1} \text { and } \underline{5} \underline{0} \underline{0} .\end{array}$ & $50.0 \%$ & $\begin{array}{l}\text { You receive } \$ 200 \text { in twelve weeks if the } \\
\text { \# rolled is between } \underline{0} \underline{0} \underline{1} \text { and } \underline{5} \underline{0} \underline{0} \text {. }\end{array}$ & $52.0 \%$ & $\mathrm{~A}$ & B \\
\hline 14 & $\begin{array}{l}\text { You receive } \$ 200 \text { in three weeks if the } \\
\text { \# rolled is between } \underline{0} \underline{0} \underline{1} \text { and } \underline{5} \underline{0} \underline{0} .\end{array}$ & $50.0 \%$ & $\begin{array}{l}\text { You receive } \$ 200 \text { in twelve weeks if the } \\
\text { \# rolled is between } \underline{0} \underline{0} 1 \text { and } \underline{5} \underline{2} \underline{2} \text {. }\end{array}$ & $52.2 \%$ & $\mathrm{~A}$ & B \\
\hline 15 & $\begin{array}{l}\text { You receive } \$ 200 \text { in three weeks if the } \\
\text { \# rolled is between } \underline{0} \underline{0} \underline{1} \text { and } \underline{5} \underline{0} \underline{0} .\end{array}$ & $50.0 \%$ & $\begin{array}{l}\text { You receive } \$ 200 \text { in twelve weeks if the } \\
\text { \# rolled is between } \underline{0} \underline{0} \underline{1} \text { and } \underline{5} \underline{2} \underline{7} \text {. }\end{array}$ & $52.7 \%$ & A & B \\
\hline 16 & $\begin{array}{l}\text { You receive } \$ 200 \text { in three weeks if the } \\
\text { \# rolled is between } \underline{0} \underline{0} \underline{1} \text { and } \underline{5} \underline{0} \underline{0} .\end{array}$ & $50.0 \%$ & $\begin{array}{l}\text { You receive } \$ 200 \text { in twelve weeks if the } \\
\text { \# rolled is between } \underline{0} \underline{0} \underline{1} \text { and } \underline{5} \underline{3} \underline{6} \text {. }\end{array}$ & $53.6 \%$ & $\mathrm{~A}$ & B \\
\hline 17 & $\begin{array}{l}\text { You receive } \$ 200 \text { in three weeks if the } \\
\text { \# rolled is between } \underline{0} \underline{0} \underline{1} \text { and } \underline{5} \underline{0} \underline{0} .\end{array}$ & $50.0 \%$ & $\begin{array}{l}\text { You receive } \$ 200 \text { in twelve weeks if the } \\
\text { \# rolled is between } \underline{0} \underline{0} \underline{1} \text { and } \underline{5} \underline{4} \underline{5} \text {. }\end{array}$ & $54.5 \%$ & A & B \\
\hline 18 & $\begin{array}{l}\text { You receive } \$ 200 \text { in three weeks if the } \\
\text { \# rolled is between } \underline{0} \underline{0} \underline{1} \text { and } \underline{5} \underline{0} \underline{0} .\end{array}$ & $50.0 \%$ & $\begin{array}{l}\text { You receive } \$ 200 \text { in twelve weeks if the } \\
\text { \# rolled is between } \underline{0} \underline{0} \underline{1} \text { and } \underline{5} \underline{6} \underline{9} \text {. }\end{array}$ & $56.9 \%$ & $\mathrm{~A}$ & B \\
\hline 19 & $\begin{array}{l}\text { You receive } \$ 200 \text { in three weeks if the } \\
\text { \# rolled is between } \underline{0} \underline{0} \underline{1} \text { and } \underline{5} \underline{0} \underline{0} .\end{array}$ & $50.0 \%$ & $\begin{array}{l}\text { You receive } \$ 200 \text { in twelve weeks if the } \\
\text { \# rolled is between } \underline{0} \underline{0} \underline{1} \text { and } \underline{5} \underline{q} \underline{4} \text {. }\end{array}$ & $59.4 \%$ & $\mathrm{~A}$ & B \\
\hline 20 & $\begin{array}{l}\text { You receive } \$ 200 \text { in three weeks if the } \\
\text { \# rolled is between } \underline{0} \underline{0} \underline{1} \text { and } \underline{5} \underline{0} \underline{0} .\end{array}$ & $50.0 \%$ & $\begin{array}{l}\text { You receive } \$ 200 \text { in twelve weeks if the } \\
\text { \# rolled is between } \underline{0} \underline{0} \underline{1} \text { and } \underline{6} \underline{4} \underline{7} \text {. }\end{array}$ & $64.7 \%$ & $\mathrm{~A}$ & B \\
\hline \multirow[t]{2}{*}{ ID N } & $\begin{array}{l}\text { Decision } \\
\text { Row Roll }\end{array}$ & & Outcome Roll & \multicolumn{3}{|c|}{$\begin{array}{l}\text { Selection for } \\
\text { Payment Roll }\end{array}$} \\
\hline & Black-20 & Red-10 & White-10 & $\begin{array}{r}\mathrm{Bl} \\
(0 \mathrm{or}\end{array}$ & $\begin{array}{l}\mathrm{k}-10 \\
=\text { pay) }\end{array}$ & \\
\hline
\end{tabular}




\section{Task R Instructions}

Each person in this room has the chance to earn a large sum of money from this part of the experiment. The amount of money you earn in this part of the experiment will depend both on your choices and also on chance. We will first explain to you the choices that you will be making, and then how your earnings are determined.

\section{YOUR CHOICES}

In this part of the experiment, you will be asked to make a series of choices. Please look at the Decision Table. Each Decision row gives you a choice between Option A and Option B. Now, please look at Decision 1 at the top. Option A pays $\$ 180.00$ if the throw of the Red 20 -sided die is 1 , and it pays $\$ 144.00$ if the throw is 2 through 20 . Option B pays $\$ 346.50$ if the throw of the die is 1 , and it pays $\$ 9.00$ if the throw is 2 through 20. The other Decisions are similar, except that as you move down the table, the chances of the higher payoff for each option increase. In fact, for Decision 20 in the bottom row, the die will not be needed since each option pays the highest payoff for sure, so your choice here is between $\$ 180.00$ or $\$ 346.50$.

You will make twenty choices. For each Decision row, you will have to choose between Option A and Option B. You may choose A for some Decision rows and B for other rows, and you may change your choice and make them in any order. So now please look at the boxes on the right side of the Decision Table. You will have to circle your choice of A or B for each of the twenty Decisions.

Even though you will make twenty Decisions, only one of these will end up possibly affecting your earnings, but you will not know in advance which Decision will be used. Each Decision has an equal chance of being used for payment.

\section{HOW YOU WILL YOU BE PAID}

Although you will complete all 20 Decisions, only one of these Decisions will be selected as the Decision that counts for payment. After you have made all 20 Decisions, we will throw a Black 20-sided die. You can see this die on the lab monitors. The number that is thrown on this 20 -sided die will determine which one of your 20 Decisions will count for payment. For example, if we throw a 12, we will look at Decision Row 12 to see if you chose Option A or Option B. We will not look at any of your other Decisions when we determine your earnings for this part of the experiment.

Next, we will throw the Red 20 -sided die to determine the monetary outcome from this task, as we described above.

After this, we will throw a black 10-sided die for the final payment phase. If the outcome is between 1 and 9 , then none of your choices in this task will count for payment. If the outcome is 0 , then your choices and the earlier rolls will determine your earnings as described above. 
Note that we will roll the dice individually for each person, and so each person is equally likely to receive payment in the final payment phase of the experiment. More than one person may be selected for payment, and each person selected will be paid the amount determined by their choices and die rolls as described above.

If you earn money in this task, we will pay you your earnings in cash before you leave today.

\section{SUMMARY}

1. You will choose Option A or Option B for each of the 20 rows of the Decision Table.

2. We will throw a black 20-sided die to determine which ONE of these Decisions will count.

3. We will look at the choice you made in this Decision, and then throw a red 20-sided die.

4. We will determine the monetary outcome based on the outcome of the red die and your choice for the selected Decision.

5. Finally, we will throw a black 10-sided die to determine whether or not you will be paid this outcome. If we throw a 1 through 9 then you will not be paid for your Decision. If we throw a 0 , then you will receive payment according to the outcome in step \#4. If you are paid, then you will receive your money before you leave today.

We will next go through a simple demonstration of this task before you make your choices. This demonstration is to help you better understand the task and will not count for money. Please listen and watch the demonstration before making your own choices.

If you have any questions, please raise your hand and one of us will come to your desk to answer it. 


\section{Task R Decision Sheet (originally printed on legal paper)}

\section{Task R Decision Table}

\begin{tabular}{|c|c|c|c|c|}
\hline Decision & Option A & Option B & & \\
\hline 1 & $\begin{array}{l}\$ 180 \text { if throw of die is } 1 \\
\$ 144 \text { if throw of die is } 2-20\end{array}$ & $\begin{array}{c}\$ 346.50 \text { if throw of die is } 1 \\
\$ 9 \text { if throw of die is } 2-20\end{array}$ & A & B \\
\hline 2 & $\begin{array}{l}\$ 180 \text { if throw of die is 1-2 } \\
\$ 144 \text { if throw of die is 3-20 }\end{array}$ & $\begin{array}{c}\$ 346.50 \text { if throw of die is } 1-2 \\
\$ 9 \text { if throw of die is } 3-20\end{array}$ & A & B \\
\hline 3 & $\begin{array}{l}\$ 180 \text { if throw of die is } 1-3 \\
\$ 144 \text { if throw of die is } 4-20\end{array}$ & $\begin{array}{c}\$ 346.50 \text { if throw of die is } 1-3 \\
\$ 9 \text { if throw of die is } 4-20\end{array}$ & A & B \\
\hline 4 & $\begin{array}{l}\$ 180 \text { if throw of die is 1-4 } \\
\$ 144 \text { if throw of die is 5-20 }\end{array}$ & $\begin{array}{l}\$ 346.50 \text { if throw of die is } 1-4 \\
\$ 9 \text { if throw of die is } 5-20\end{array}$ & A & B \\
\hline 5 & $\begin{array}{l}\$ 180 \text { if throw of die is } 1-5 \\
\$ 144 \text { if throw of die is 6-20 }\end{array}$ & $\begin{array}{c}\$ 346.50 \text { if throw of die is } 1-5 \\
\$ 9 \text { if throw of die is } 6-20\end{array}$ & A & B \\
\hline 6 & $\begin{array}{l}\$ 180 \text { if throw of die is } 1-6 \\
\$ 144 \text { if throw of die is } 7-20\end{array}$ & $\begin{array}{c}\$ 346.50 \text { if throw of die is } 1-6 \\
\$ 9 \text { if throw of die is } 7-20\end{array}$ & A & B \\
\hline 7 & $\begin{array}{l}\$ 180 \text { if throw of die is 1-7 } \\
\$ 144 \text { if throw of die is 8-20 }\end{array}$ & $\begin{array}{c}\$ 346.50 \text { if throw of die is 1-7 } \\
\$ 9 \text { if throw of die is } 8-20\end{array}$ & A & B \\
\hline 8 & $\begin{array}{l}\$ 180 \text { if throw of die is } 1-8 \\
\$ 144 \text { if throw of die is } 9-20\end{array}$ & $\begin{array}{c}\$ 346.50 \text { if throw of die is 1-8 } \\
\$ 9 \text { if throw of die is } 9-20\end{array}$ & A & B \\
\hline 9 & $\begin{array}{l}\$ 180 \text { if throw of die is 1-9 } \\
\$ 144 \text { if throw of die is } 10-20\end{array}$ & $\begin{array}{c}\$ 346.50 \text { if throw of die is } 1-9 \\
\$ 9 \text { if throw of die is } 10-20\end{array}$ & A & B \\
\hline 10 & $\begin{array}{l}\$ 180 \text { if throw of die is } 1-10 \\
\$ 144 \text { if throw of die is } 11-20\end{array}$ & $\begin{array}{c}\$ 346.50 \text { if throw of die is } 1-10 \\
\$ 9 \text { if throw of die is } 11-20\end{array}$ & A & B \\
\hline 11 & $\begin{array}{l}\$ 180 \text { if throw of die is } 1-11 \\
\$ 144 \text { if throw of die is } 12-20\end{array}$ & $\begin{array}{l}\$ 346.50 \text { if throw of die is } 1-11 \\
\$ 9 \text { if throw of die is } 12-20\end{array}$ & A & B \\
\hline 12 & $\begin{array}{l}\$ 180 \text { if throw of die is 1-12 } \\
\$ 144 \text { if throw of die is } 13-20\end{array}$ & $\begin{array}{c}\$ 346.50 \text { if throw of die is } 1-12 \\
\$ 9 \text { if throw of die is } 13-20\end{array}$ & A & B \\
\hline 13 & $\begin{array}{l}\$ 180 \text { if throw of die is } 1-13 \\
\$ 144 \text { if throw of die is } 14-20\end{array}$ & $\begin{array}{l}\$ 346.50 \text { if throw of die is } 1-13 \\
\$ 9 \text { if throw of die is } 14-20\end{array}$ & A & B \\
\hline 14 & $\begin{array}{l}\$ 180 \text { if throw of die is } 1-14 \\
\$ 144 \text { if throw of die is } 15-20\end{array}$ & $\begin{array}{c}\$ 346.50 \text { if throw of die is } 1-14 \\
\$ 9 \text { if throw of die is } 15-20\end{array}$ & A & B \\
\hline 15 & $\begin{array}{l}\$ 180 \text { if throw of die is } 1-15 \\
\$ 144 \text { if throw of die is } 16-20\end{array}$ & $\begin{array}{l}\$ 346.50 \text { if throw of die is } 1-15 \\
\$ 9 \text { if throw of die is } 16-20\end{array}$ & A & B \\
\hline 16 & $\begin{array}{l}\$ 180 \text { if throw of die is } 1-16 \\
\$ 144 \text { if throw of die is } 17-20\end{array}$ & $\begin{array}{c}\$ 346.50 \text { if throw of die is } 1-16 \\
\$ 9 \text { if throw of die is } 17-20\end{array}$ & A & B \\
\hline 17 & $\begin{array}{l}\$ 180 \text { if throw of die is } 1-17 \\
\$ 144 \text { if throw of die is } 18-20\end{array}$ & $\begin{array}{c}\$ 346.50 \text { if throw of die is } 1-17 \\
\$ 9 \text { if throw of die is } 18-20\end{array}$ & A & B \\
\hline 18 & $\begin{array}{l}\$ 180 \text { if throw of die is } 1-18 \\
\$ 144 \text { if throw of die is } 19-20\end{array}$ & $\begin{array}{c}\$ 346.50 \text { if throw of die is } 1-18 \\
\$ 9 \text { if throw of die is } 19-20\end{array}$ & A & B \\
\hline 19 & $\begin{array}{c}\$ 180 \text { if throw of die is } 1-19 \\
\$ 144 \text { if throw of die is } 20\end{array}$ & $\begin{array}{c}\$ 346.50 \text { if throw of die is } 1-19 \\
\$ 9 \text { if throw of die is } 20\end{array}$ & A & B \\
\hline 20 & $\$ 180$ if throw of die is $1-20$ & $\$ 346.50$ if throw of die is $1-20$ & A & B \\
\hline \multirow[t]{2}{*}{ ID Nu } & $\begin{array}{l}\text { Decision } \\
\text { Row Roll }\end{array}$ & $\begin{array}{l}\text { Selection for } \\
\text { Payment Roll }\end{array}$ & & \\
\hline & Black-20 & $\begin{array}{l}\text { Black-10 } \\
(0=\text { pay })\end{array}$ & & \\
\hline
\end{tabular}




\section{Experiment 2 Introductory Instructions}

You are now participating in a decision-making experiment. Based on your decisions in this experiment, you can earn money that will be paid to you in cash. It is important that you understand all instructions before making your choices in this experiment.

Please turn off your cell phone, laptop computer, or any other device you may have brought with you. Please do not talk with others seated in the room for the duration of the experiment. If at any point you have a question, please raise your hand and we will address it as soon as possible. Also, please remove everything from your desk except for your folder, these instructions, and something to write with.

The experiment consists of four decision-making tasks. You have earned $\$ 5$ for arriving for the experiment on time, and you will be paid another $\$ 5$ for each of the four tasks that you complete. So, if you complete all four decision-making tasks you will earn $\$ 25$ for participating in today's experiment.

In addition to your participation payment, you may earn considerably more from each task. Each of the decision tasks and the potential earnings from these tasks will be explained in detail as we proceed through the instructions. Your earnings from each of the four tasks will be calculated at the end of todays session after all four tasks are completed.

However, it is important that you know that you will not receive any earnings, other than your participation payments, unless you complete all four decision-making tasks. For example, if you leave right now

you will be paid $\$ 5$ for coming to todays experiment. On the other hand if you leave after completing two of the four tasks today, you will receive $\$ 15$ but you will not be eligible to receive any other payments from todays experiment. If you complete all four tasks, you will receive your $\$ 25$ participation payment and be eligible to receive additional earnings based on your decisions in the four tasks.

Are there any questions so far?

\section{Experiment 2 Main Instructions}

In today's experiment you will participate in four Decision-Making Tasks. Each Task involves the chance to earn $\$ 100$ that may be paid to you today, or on a specified date later in the semester. Whether you earn this $\$ 100$ (in addition to your participation payment) and when you receive the $\$ 100$ will depend on both your choices in these Tasks and also on chance.

Even though you will participate in four Decision-Making Tasks, only one of these four tasks will count for payment. After you have completed all Tasks in today's experiment, we will randomly choose one of them that will be used to determine any additional earnings. To choose the Task for payment, we will throw a 6-sided die for each person individually: 
- If we throw a 1 Task 1 will count for payment.

- If we throw a 2 Task 2 will count for payment.

- If we throw a 3 Task 3 will count for payment.

- If we throw a 4 Task 4 will count for payment.

- If we throw a 5 or 6 we will throw again until a 1 through 4 comes up.

So, if I throw a 3 for one person, that persons additional earnings will be based upon Task 3 only. If I throw a 4 for another person, that person will be will be paid based upon Task 4 only.

We will first explain to you the choices that you will be making, and then how your earnings will determined.

\section{YOUR CHOICES}

In each part of this experiment, you will be asked to make a series of choices between Option A and Option B. On the lab monitors, you can see four 10-sided die: a red die, a white die, a blue die, and a black die.

Your earnings in this part of the experiment depend, in part, on the outcome from rolling these four die. We will throw all four dice, and then record the outcome as a four digit number:

\section{RedDie\# WhiteDie\# BlueDie\# BlackDie\#}

For example, if we threw a "6" on the Red Die, a "4" on the White Die, a "0" on the Blue Die, and a "2" on the Black Die, the number recorded would be 6402 . On the other hand, if we threw a "0" on the Red Die, "6" on the White Die, a "4" on the Blue Die, and a "2" on the Black Die, the number recorded would be 0642. Notice that there are ten thousand possible outcomes of the drawing. They can be listed as:

$$
\{0001,0002,0003,0004, \ldots, 9996,9997,9998,9999,0000\}
$$

Each of these numbers has a 1-in-10,000 chance of being thrown (if four zeros are thrown, this will represent an outcome of 10,000).

Please look at the Sample Decision Table. This sample table is being used to demonstrate the types of decisions you will be making and how the payments will be determined. The payment dates and the die rolls listed are different than those you will actually see during the experiment.

In this sample table, each Decision row gives you a choice between Option A and Option B. As an example, look at the row for Decision 2. Option A pays $\$ 100$ in 7 days (one week) if the number thrown 
is between 0001 to 5000 . Thus, there are 5,000-in-10,000 chances of receiving $\$ 100$ if you choose Option A. This represents a $50 \%$ chance of winning. Now look at Option B for Decision 2. Option B pays $\$ 100$ in 35 days ( 5 weeks) if the number thrown is between 0001 to 5004 . There are 5,004 -in-10,000 chances $(50.4 \%)$ that the number drawn will be in this range. As you move down the table, Option A is always the same, but with Option B the chances of winning increase.

Looking down the rows of the Sample Decision Table, you can see that you have 14 Decisions to make. In each of these Decisions, Option A represents a chance to earn $\$ 100$ in 7 days if the number thrown on the die is between 0001 and 5000. In each of these Decisions, Option B represents a chance to earn $\$ 100$ in 35 days, with the chance of earning this money increasing as you move down the rows of the table. For example, in Decision 12, there is a 5,000-in-10,000 (50 percent) chance of earning $\$ 100$ in 7 days if you choose Option A and a 5,116-in-10,000 (51.16 percent) chance of earning $\$ 100$ in 35 days if you choose Option B.

In each of the four Decision-Making Tasks, you will make 14 choices that are similar to those in this example. Each involves a choice between a chance to receive $\$ 100$ on two different dates. The dates on which you would be paid, and the chance of receiving the $\$ 100$, will be different in each of the four Tasks (and all four are different than those on the Sample Decision Sheet).

For each Decision row, you will have to choose between Option A and Option B. You may choose A for some Decision rows and B for other rows, and you may change your choices and make them in any order. So now please look at the boxes on the right side of the Sample Decision Sheet. If this were an actual Task, you would circle your choice of A or B for each of the 14 Decisions.

Even though you will make 14 Decisions in each Task, only one of these 14 Decisions will end up affecting your earnings (for the one Task chosen for payment), but you will not know in advance which Decision will be used. Each Decision has an equal chance of being used for payment.

\section{HOW YOU WILL YOU BE PAID}

For each Decision row, you will choose whether you prefer A or B for that row. For the Decision-Making Task that is chosen for payment, we will throw a 20-sided die. You can see this die on the lab monitors. The number that is thrown on the 20-sided die will determine which one of your 14 Decisions will count for payment (if I throw 15-20, I will throw the die again). For example, if we throw a 12, we will look at Decision Row 12 to see if you chose Option A or Option B. We will not look at any of your other Decisions when we determine your earnings.

Next, we will throw the four colored 10 -sided dice to determine whether the monetary outcome is $\$ 100$, as we described above. Continuing with the example, for Decision 12 in the Sample Decision Table, the table below illustrates the outcomes that would occur depending on the 4-digit die throw and whether you chose Option A or Option B in the Sample Decision Sheet. 


\begin{tabular}{ccc}
\hline Die Throw & $\begin{array}{c}\text { Outcome If You } \\
\text { Choose Option A }\end{array}$ & $\begin{array}{c}\text { Outcome If You } \\
\text { Choose Option B }\end{array}$ \\
\hline $0001-5000$ & $\$ 100$ in 7 days & $\$ 100$ in 35 days \\
$5001-5116$ & $\$ 0$ & $\$ 100$ in 35 days \\
$5117-0000$ & $\$ 0$ & $\$ 0$ \\
\hline
\end{tabular}

Suppose instead that when we threw the 20 -sided die, we had determined that Decision 3 was the one that counts for payment. In this case, the table below illustrates the outcomes that would occur depending on the 4-digit die throw and whether you chose Option A or Option B.

\begin{tabular}{ccc}
\hline Die Throw & $\begin{array}{c}\text { Outcome If You } \\
\text { Choose Option A }\end{array}$ & $\begin{array}{c}\text { Outcome If You } \\
\text { Choose Option B }\end{array}$ \\
\hline $0001-5000$ & $\$ 100$ in 7 days & $\$ 100$ in 35 days \\
$5001-5008$ & $\$ 0$ & $\$ 100$ in 35 days \\
$5009-0000$ & $\$ 0$ & $\$ 0$ \\
\hline
\end{tabular}

Recall that each person will see a different die roll - so some of you may earn $\$ 100$ and others will earn nothing. It depends on the die rolls and on your choice of Option A or Option B.

If the outcome results in you earning $\$ 100$ on a later date, I will give you a certificate for $\$ 100$ redeemable in cash here in the Andrew Young School Building on the date specified in the Decision selected to be paid. You can pick up your $\$ 100$ earnings at any time on or after that date. If you do earn this money, then at the end of the experiment we will give you more detailed instructions for redeeming your certificate and the location in this building where you will go to redeem your certificate. Regardless of whether or not you earn this $\$ 100$, you will still receive the $\$ 25$ participation payment if you complete all four Decision-Making Tasks.

\section{SUMMARY}

1. We will hand out four separate Decision Tables to you, one at a time. For each Decision Table you should pay careful attention to all of the information you are given. The time at which you may receive payment, and the chance of winning, will be different for each Decision task and all will be different from the Sample Decision Sheet we have used in the instructions.

2. For each Decision Task, you will make a choice of Option A or Option B for each of the 14 rows of the Decision Table. You can choose A for some rows and B for other rows.

3. After all four tasks are complete, we will give you a short survey to fill out.

4. We will call you outside of the lab one at a time to determine your earnings individually and privately.

5. We will throw a 6-sided die to determine which ONE of the four Decision-Making Tasks will count for payment: 
- If we throw a 1 - Task 1 will count for payment.

. If we throw a 2 - Task 2 will count for payment.

. If we throw a 3 - Task 3 will count for payment.

. If we throw a 4 - Task 4 will count for payment.

- If we throw a 5 or 6 - we will throw again until a 1 through 4 comes up.

6. For the ONE decision-making task that is selected in Step 5, we will throw a 20-sided die to determine which ONE of your 14 Decisions will count. (If we throw a number between 15 and 20 we will throw the die again until a number between 1 and 14 comes up.)

7. We will look at the choice you made in this Decision, and then throw the four 10-sided dice.

8. We will look at the four-digit-number that comes from the dice roll and also at your choice for this one Decision to determine the monetary outcome: receive $\$ 0$, or receive $\$ 100$ - and when you will receive $\$ 100$.

9. You will be paid for your participation today. If the outcome is to receive $\$ 100$ in the future, we will give you a certificate for this and instructions on where to come back and receive your earnings.

If you have any questions, please raise your hand and one of us will come to your desk to answer it. 


\section{Experiment 2 Task A Decision Sheet (Baseline)}

\section{Decision Table}

\begin{tabular}{|c|c|c|c|c|c|c|}
\hline \multirow[t]{2}{*}{ Decision } & \multicolumn{2}{|l|}{$\begin{array}{c}\text { Option } A \\
\text { (Pays } \$ 100 \text { in } 14 \text { days) } \\
\end{array}$} & \multicolumn{2}{|l|}{$\begin{array}{c}\text { Option B } \\
\text { (Pays } \$ 100 \text { in } 63 \text { days) } \\
\end{array}$} & \multicolumn{2}{|c|}{$\begin{array}{c}\text { Preferred } \\
\text { Option } \\
\text { (Circle } \\
\text { A or B) } \\
\end{array}$} \\
\hline & Winning Numbers for Option A & $\begin{array}{l}\text { Chances of } \\
\text { winning }\end{array}$ & Winning Numbers for Option B & $\begin{array}{l}\text { Chances of } \\
\text { winning }\end{array}$ & & \\
\hline 1 & $\begin{array}{l}\text { You receive } \$ 100 \text { in } 14 \text { days if the } \\
\text { \# rolled is between } \underline{0} \underline{0} \underline{0} \underline{1} \text { and } \underline{\underline{0}} \underline{0} \underline{0} \underline{0} .\end{array}$ & $50.00 \%$ & $\begin{array}{l}\text { You receive } \$ 100 \text { in } 63 \text { days if the \# } \\
\text { rolled is between } \underline{0} \underline{0} \underline{0} \underline{1} \text { and } \underline{\underline{0}} \underline{0} \underline{0} \underline{0} \text {. }\end{array}$ & $50.00 \%$ & A & B \\
\hline 2 & $\begin{array}{l}\text { You receive } \$ 100 \text { in } 14 \text { days if the } \\
\text { \# rolled is between } \underline{0} \underline{0} \underline{0} \underline{1} \text { and } \underline{5} \underline{0} \underline{0} \underline{0} \text {. }\end{array}$ & $50.00 \%$ & $\begin{array}{l}\text { You receive } \$ 100 \text { in } 63 \text { days if the } \\
\text { \# rolled is between } \underline{0} \underline{0} \underline{0} \underline{1} \text { and } 5 \underline{0} \underline{0} 7 .\end{array}$ & $50.07 \%$ & A & B \\
\hline 3 & $\begin{array}{l}\text { You receive } \$ 100 \text { in } 14 \text { days if the } \\
\text { \# rolled is between } \underline{0} \underline{0} \underline{0} \underline{1} \text { and } \underline{5} \underline{0} \underline{0} \underline{0} \text {. }\end{array}$ & $50.00 \%$ & $\begin{array}{l}\text { You receive } \$ 100 \text { in } 63 \text { days if the } \\
\text { \# rolled is between } \underline{0} \underline{0} \underline{0} \underline{1} \text { and } \underline{\underline{0}} \underline{1} \underline{1} .\end{array}$ & $50.13 \%$ & A & B \\
\hline 4 & $\begin{array}{l}\text { You receive } \$ 100 \text { in } 14 \text { days if the } \\
\text { \# rolled is between } \underline{0} \underline{0} \underline{0} \underline{1} \text { and } \underline{5} \underline{0} \underline{0} \underline{0} \underline{0} \text {. }\end{array}$ & $50.00 \%$ & $\begin{array}{l}\text { You receive } \$ 100 \text { in } 63 \text { days if the } \\
\text { \# rolled is between } \underline{0} \underline{0} \underline{0} \underline{1} \text { and } \underline{\underline{0}} \underline{2} \underline{\mathrm{Z}} .\end{array}$ & $50.27 \%$ & A & B \\
\hline 5 & $\begin{array}{l}\text { You receive } \$ 100 \text { in } 14 \text { days if the } \\
\text { \# rolled is between } \underline{0} \underline{0} \underline{0} \underline{1} \text { and } 5 \underline{0} \underline{0} \underline{0} \underline{0} .\end{array}$ & $50.00 \%$ & $\begin{array}{l}\text { You receive } \$ 100 \text { in } 63 \text { days if the } \\
\text { \# rolled is between } \underline{0} \underline{0} \underline{0} \underline{1} \text { and } 5 \underline{0} 4 \underline{0} .\end{array}$ & $50.40 \%$ & A & B \\
\hline 6 & $\begin{array}{l}\text { You receive } \$ 100 \text { in } 14 \text { days if the } \\
\text { \# rolled is between } \underline{0} \underline{0} \underline{0} \underline{1} \text { and } \underline{5} \underline{0} \underline{0} \underline{0} .\end{array}$ & $50.00 \%$ & $\begin{array}{l}\text { You receive } \$ 100 \text { in } 63 \text { days if the } \\
\text { \# rolled is between } \underline{0} \underline{0} \underline{0} \underline{1} \text { and } 5 \underline{0} 5 \underline{4} .\end{array}$ & $50.54 \%$ & A & B \\
\hline 7 & $\begin{array}{l}\text { You receive } \$ 100 \text { in } 14 \text { days if the } \\
\text { \# rolled is between } \underline{0} \underline{0} \underline{0} \underline{1} \text { and } \underline{5} \underline{0} \underline{0} \underline{0} \text {. }\end{array}$ & $50.00 \%$ & $\begin{array}{l}\text { You receive } \$ 100 \text { in } 63 \text { days if the } \\
\text { \# rolled is between } \underline{0} \underline{0} \underline{0} \underline{1} \text { and } 5 \underline{0} \underline{6} \underline{8} .\end{array}$ & $50.68 \%$ & A & B \\
\hline 8 & $\begin{array}{l}\text { You receive } \$ 100 \text { in } 14 \text { days if the } \\
\text { \# rolled is between } \underline{0} \underline{0} \underline{0} \underline{1} \text { and } \underline{5} \underline{0} \underline{0} \underline{0} .\end{array}$ & $50.00 \%$ & $\begin{array}{l}\text { You receive } \$ 100 \text { in } 63 \text { days if the } \\
\text { \# rolled is between } \underline{0} \underline{0} \underline{0} \underline{1} \text { and } 5 \underline{0} \underline{8} \underline{1} .\end{array}$ & $50.81 \%$ & A & B \\
\hline 9 & $\begin{array}{l}\text { You receive } \$ 100 \text { in } 14 \text { days if the } \\
\text { \# rolled is between } \underline{0} \underline{0} \underline{0} \underline{1} \text { and } \underline{5} \underline{0} \underline{0} \underline{0} .\end{array}$ & $50.00 \%$ & $\begin{array}{l}\text { You receive } \$ 100 \text { in } 63 \text { days if the } \\
\text { \# rolled is between } \underline{0} \underline{0} \underline{0} \underline{1} \text { and } \underline{1} \underline{1} \underline{\mathrm{o}} 9 .\end{array}$ & $51.09 \%$ & A & B \\
\hline 10 & $\begin{array}{l}\text { You receive } \$ 100 \text { in } 14 \text { days if the } \\
\text { \# rolled is between } \underline{0} \underline{0} \underline{0} \underline{1} \text { and } \underline{5} \underline{0} \underline{0} \underline{0} .\end{array}$ & $50.00 \%$ & $\begin{array}{l}\text { You receive } \$ 100 \text { in } 63 \text { days if the } \\
\text { \# rolled is between } \underline{0} \underline{0} \underline{0} \underline{1} \text { and } 5 \underline{1} \underline{\underline{6}} \underline{6} .\end{array}$ & $51.36 \%$ & A & B \\
\hline 11 & $\begin{array}{l}\text { You receive } \$ 100 \text { in } 14 \text { days if the } \\
\text { \# rolled is between } \underline{0} \underline{0} \underline{0} \underline{1} \text { and } \underline{5} \underline{0} \underline{0} \underline{0} \text {. }\end{array}$ & $50.00 \%$ & $\begin{array}{l}\text { You receive } \$ 100 \text { in } 63 \text { days if the } \\
\text { \# rolled is between } \underline{0} \underline{0} \underline{0} \underline{1} \text { and } 5 \underline{1} \mathbf{Z} \underline{1} .\end{array}$ & $51.71 \%$ & A & B \\
\hline 12 & $\begin{array}{l}\text { You receive } \$ 100 \text { in } 14 \text { days if the } \\
\text { \# rolled is between } \underline{0} \underline{0} \underline{0} \underline{1} \text { and } \underline{5} \underline{0} \underline{0} \underline{0} .\end{array}$ & $50.00 \%$ & $\begin{array}{l}\text { You receive } \$ 100 \text { in } 63 \text { days if the } \\
\text { \# rolled is between } \underline{0} \underline{0} \underline{0} \underline{1} \text { and } \underline{\underline{2}} \underline{\mathbf{0}} \underline{5} .\end{array}$ & $52.05 \%$ & A & B \\
\hline 13 & $\begin{array}{l}\text { You receive } \$ 100 \text { in } 14 \text { days if the } \\
\text { \# rolled is between } \underline{0} \underline{0} \underline{0} \underline{1} \text { and } \underline{5} \underline{0} \underline{0} \underline{0} \text {. }\end{array}$ & $50.00 \%$ & $\begin{array}{l}\text { You receive } \$ 100 \text { in } 63 \text { days if the } \\
\text { \# rolled is between } \underline{0} \underline{0} \underline{0} \underline{1} \text { and } 5 \underline{2} \underline{z} \underline{6} \text {. }\end{array}$ & $52.76 \%$ & A & B \\
\hline 14 & $\begin{array}{l}\text { You receive } \$ 100 \text { in } 14 \text { days if the } \\
\text { \# rolled is between } \underline{0} \underline{0} \underline{0} \underline{1} \text { and } \underline{5} \underline{0} \underline{0} \underline{0} \text {. }\end{array}$ & $50.00 \%$ & $\begin{array}{l}\text { You receive } \$ 100 \text { in } 63 \text { days if the } \\
\text { \# rolled is between } \underline{0} \underline{0} \underline{0} \underline{1} \text { and } 5 \underline{5} \underline{2} .\end{array}$ & $55.29 \%$ & A & B \\
\hline
\end{tabular}

Task Number

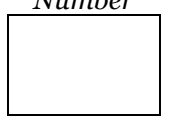

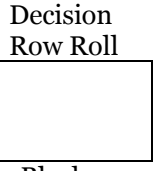

Black-20

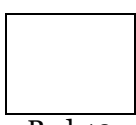

Red-10
Outcome Roll

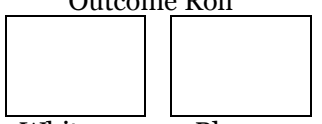

Blue-10

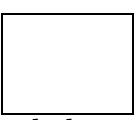

Black-10 


\section{Experiment 2 Task B Decision Sheet (No FED)}

\section{Decision Table}

\begin{tabular}{|c|c|c|c|c|c|c|}
\hline \multirow[t]{2}{*}{ Decision } & \multicolumn{2}{|l|}{$\begin{array}{c}\text { Option A } \\
\text { (Pays \$10o today) }\end{array}$} & \multicolumn{2}{|l|}{$\begin{array}{c}\text { Option B } \\
\text { (Pays \$100 in } 49 \text { days) } \\
\end{array}$} & \multicolumn{2}{|c|}{$\begin{array}{c}\text { Preferred } \\
\text { Option } \\
\text { (Circle } \\
\text { A or B) } \\
\end{array}$} \\
\hline & Winning Numbers for Option A & $\begin{array}{l}\text { Chances of } \\
\text { winning }\end{array}$ & Winning Numbers for Option B & $\begin{array}{l}\text { Chances of } \\
\text { winning }\end{array}$ & & \\
\hline 1 & $\begin{array}{l}\text { You receive } \$ 100 \text { today if the } \\
\text { \# rolled is between } \underline{0} \underline{0} \underline{0} \underline{1} \text { and } \underline{\underline{0}} \underline{\mathrm{o}} \underline{\mathrm{o}} \underline{ } \text {. }\end{array}$ & $50.00 \%$ & $\begin{array}{l}\text { You receive } \$ 100 \text { in } 49 \text { days if the \# } \\
\text { rolled is between } \underline{0} \underline{0} \underline{0} \underline{1} \text { and } \underline{\underline{0}} \underline{0} \underline{0} \underline{0} \text {. }\end{array}$ & $50.00 \%$ & A & B \\
\hline 2 & $\begin{array}{l}\text { You receive } \$ 100 \text { today if the } \\
\text { \# rolled is between } \underline{0} \underline{0} \underline{0} \underline{1} \text { and } \underline{5} \underline{0} \underline{0} \underline{0} \text {. }\end{array}$ & $50.00 \%$ & $\begin{array}{l}\text { You receive } \$ 100 \text { in } 49 \text { days if the } \\
\text { \# rolled is between } \underline{0} \underline{0} \underline{0} \underline{1} \text { and } 5 \underline{0} \underline{0} 7 .\end{array}$ & $50.07 \%$ & A & B \\
\hline 3 & $\begin{array}{l}\text { You receive } \$ 100 \text { today if the } \\
\text { \# rolled is between } \underline{0} \underline{0} \underline{0} \underline{1} \text { and } \underline{5} \underline{0} \underline{o} \underline{0} \text {. }\end{array}$ & $50.00 \%$ & $\begin{array}{l}\text { You receive } \$ 100 \text { in } 49 \text { days if the } \\
\text { \# rolled is between } \underline{0} \underline{0} \underline{0} \underline{1} \text { and } \underline{\underline{0}} \underline{1} \underline{1} .\end{array}$ & $50.13 \%$ & A & B \\
\hline 4 & $\begin{array}{l}\text { You receive } \$ 100 \text { today if the } \\
\text { \# rolled is between } \underline{0} \underline{0} \underline{0} \underline{1} \text { and } \underline{5} \underline{\mathrm{o}} \underline{\mathrm{o}} \underline{\mathrm{o}} .\end{array}$ & $50.00 \%$ & $\begin{array}{l}\text { You receive } \$ 100 \text { in } 49 \text { days if the } \\
\text { \# rolled is between } \underline{0} \underline{0} \underline{0} \underline{1} \text { and } \underline{\underline{0}} \underline{2} \underline{\mathrm{Z}} .\end{array}$ & $50.27 \%$ & A & B \\
\hline 5 & $\begin{array}{l}\text { You receive } \$ 100 \text { today if the } \\
\text { \# rolled is between } \underline{0} \underline{0} \underline{0} \underline{1} \text { and } \underline{5} \underline{0} \underline{0} \underline{0} .\end{array}$ & $50.00 \%$ & $\begin{array}{l}\text { You receive } \$ 100 \text { in } 49 \text { days if the } \\
\text { \# rolled is between } \underline{0} \underline{0} \underline{0} \underline{1} \text { and } 5 \underline{0} \underline{\underline{0}} .\end{array}$ & $50.40 \%$ & A & B \\
\hline 6 & $\begin{array}{l}\text { You receive } \$ 100 \text { today if the } \\
\text { \# rolled is between } \underline{0} \underline{0} \underline{0} \underline{1} \text { and } \underline{5} \underline{0} \underline{0} \underline{0} \text {. }\end{array}$ & $50.00 \%$ & $\begin{array}{l}\text { You receive } \$ 100 \text { in } 49 \text { days if the } \\
\text { \# rolled is between } \underline{0} \underline{0} \underline{0} \underline{1} \text { and } 5 \underline{0} 5 \underline{4} .\end{array}$ & $50.54 \%$ & A & B \\
\hline 7 & $\begin{array}{l}\text { You receive } \$ 100 \text { today if the } \\
\text { \# rolled is between } \underline{0} \underline{0} \underline{0} \underline{1} \text { and } \underline{5} \underline{0} \underline{0} \underline{0} \text {. }\end{array}$ & $50.00 \%$ & $\begin{array}{l}\text { You receive } \$ 100 \text { in } 49 \text { days if the } \\
\text { \# rolled is between } \underline{0} \underline{0} \underline{0} \underline{1} \text { and } 5 \underline{0} \underline{6} \underline{8} .\end{array}$ & $50.68 \%$ & A & B \\
\hline 8 & $\begin{array}{l}\text { You receive } \$ 100 \text { today if the } \\
\text { \# rolled is between } \underline{0} \underline{0} \underline{0} \underline{1} \text { and } \underline{\underline{0}} \underline{\mathrm{o}} \underline{\mathrm{o}} \underline{\text {. }}\end{array}$ & $50.00 \%$ & $\begin{array}{l}\text { You receive } \$ 100 \text { in } 49 \text { days if the } \\
\text { \# rolled is between } \underline{0} \underline{0} \underline{0} \underline{1} \text { and } 5 \underline{0} \underline{8} \underline{1} .\end{array}$ & $50.81 \%$ & A & B \\
\hline 9 & $\begin{array}{l}\text { You receive } \$ 100 \text { today if the } \\
\text { \# rolled is between } \underline{0} \underline{0} \underline{0} \underline{1} \text { and } \underline{5} \underline{\mathrm{o}} \underline{\mathrm{o}} \underline{\mathrm{o}} \text {. }\end{array}$ & $50.00 \%$ & $\begin{array}{l}\text { You receive } \$ 100 \text { in } 49 \text { days if the } \\
\text { \# rolled is between } \underline{0} \underline{0} \underline{0} \underline{1} \text { and } \underline{1} \underline{1} \underline{0} 9 .\end{array}$ & $51.09 \%$ & A & B \\
\hline 10 & $\begin{array}{l}\text { You receive } \$ 100 \text { today if the } \\
\text { \# rolled is between } \underline{0} \underline{0} \underline{0} \underline{1} \text { and } \underline{5} \underline{0} \underline{0} \underline{0} .\end{array}$ & $50.00 \%$ & $\begin{array}{l}\text { You receive } \$ 100 \text { in } 49 \text { days if the } \\
\text { \# rolled is between } \underline{0} \underline{0} \underline{0} \underline{1} \text { and } 5 \underline{1} \underline{\underline{6}} \underline{6} .\end{array}$ & $51.36 \%$ & A & B \\
\hline 11 & $\begin{array}{l}\text { You receive } \$ 100 \text { today if the } \\
\text { \# rolled is between } \underline{0} \underline{0} \underline{0} \underline{1} \text { and } \underline{5} \underline{0} \underline{0} \underline{0} \text {. }\end{array}$ & $50.00 \%$ & $\begin{array}{l}\text { You receive } \$ 100 \text { in } 49 \text { days if the } \\
\text { \# rolled is between } \underline{0} \underline{0} \underline{0} \underline{1} \text { and } 5 \underline{1} \mathbf{Z} \underline{1} .\end{array}$ & $51.71 \%$ & A & B \\
\hline 12 & $\begin{array}{l}\text { You receive } \$ 100 \text { today if the } \\
\text { \# rolled is between } \underline{0} \underline{0} \underline{0} \underline{1} \text { and } \underline{5} \underline{0} \underline{0} \underline{0} \text {. }\end{array}$ & $50.00 \%$ & $\begin{array}{l}\text { You receive } \$ 100 \text { in } 49 \text { days if the } \\
\text { \# rolled is between } \underline{0} \underline{0} \underline{0} \underline{1} \text { and } \underline{\underline{2}} \underline{\mathbf{0}} \underline{5} .\end{array}$ & $52.05 \%$ & A & B \\
\hline 13 & $\begin{array}{l}\text { You receive } \$ 100 \text { today if the } \\
\text { \# rolled is between } \underline{0} \underline{0} \underline{0} \underline{1} \text { and } \underline{5} \underline{0} \underline{0} \underline{0} \text {. }\end{array}$ & $50.00 \%$ & $\begin{array}{l}\text { You receive } \$ 100 \text { in } 49 \text { days if the } \\
\text { \# rolled is between } \underline{0} \underline{0} \underline{0} \underline{1} \text { and } 5 \underline{2} \underline{z} \underline{6} \text {. }\end{array}$ & $52.76 \%$ & A & B \\
\hline 14 & $\begin{array}{l}\text { You receive } \$ 100 \text { today if the } \\
\text { \# rolled is between } \underline{0} \underline{0} \underline{0} \underline{1} \text { and } \underline{5} \underline{0} \underline{0} \underline{0} \text {. }\end{array}$ & $50.00 \%$ & $\begin{array}{l}\text { You receive } \$ 100 \text { in } 49 \text { days if the } \\
\text { \# rolled is between } \underline{0} \underline{0} \underline{0} \underline{1} \text { and } 5 \underline{5} \underline{2} .\end{array}$ & $55.29 \%$ & A & B \\
\hline
\end{tabular}

Task Number

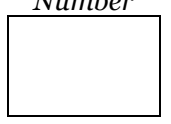

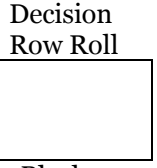

Black-20

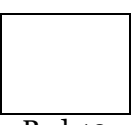

Red-10
Outcome Roll

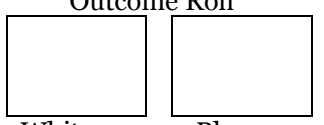

White-10
Blue-10

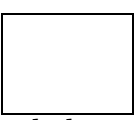

Black-10 


\section{Experiment 2 Task C Decision Sheet (Short FED)}

\section{Decision Table}

\begin{tabular}{|c|c|c|c|c|c|c|}
\hline \multirow[t]{2}{*}{ Decision } & \multicolumn{2}{|l|}{$\begin{array}{c}\text { Option A } \\
\text { (Pays } \$ 100 \text { in } 1 \text { day) } \\
\end{array}$} & \multicolumn{2}{|l|}{$\begin{array}{c}\text { Option B } \\
\text { (Pays \$100 in 50 days) } \\
\end{array}$} & \multicolumn{2}{|c|}{$\begin{array}{c}\text { Preferred } \\
\text { Option } \\
\text { (Circle } \\
\text { A or B) } \\
\end{array}$} \\
\hline & Winning Numbers for Option A & $\begin{array}{l}\text { Chances of } \\
\text { winning }\end{array}$ & Winning Numbers for Option B & $\begin{array}{l}\text { Chances of } \\
\text { winning }\end{array}$ & & \\
\hline 1 & $\begin{array}{l}\text { You receive } \$ 100 \text { in } 1 \text { day if the } \\
\text { \# rolled is between } \underline{0} \underline{0} \underline{0} \underline{1} \text { and } \underline{\underline{0}} \underline{0} \underline{0} \underline{0} \text {. }\end{array}$ & $50.00 \%$ & $\begin{array}{l}\text { You receive } \$ 100 \text { in } 50 \text { days if the \# } \\
\text { rolled is between } \underline{0} \underline{0} \underline{0} \underline{1} \text { and } \underline{\underline{0}} \underline{0} \underline{0} \underline{0} \text {. }\end{array}$ & $50.00 \%$ & A & B \\
\hline 2 & $\begin{array}{l}\text { You receive } \$ 100 \text { in } \underline{1} \text { day if the } \\
\text { \# rolled is between } \underline{0} \underline{0} \underline{0} \underline{1} \text { and } \underline{5} \underline{0} \underline{0} \underline{0} .\end{array}$ & $50.00 \%$ & $\begin{array}{l}\text { You receive } \$ 100 \text { in } 50 \text { days if the } \\
\text { \# rolled is between } \underline{0} \underline{0} \underline{0} \underline{1} \text { and } 5 \underline{0} \underline{0} 7 .\end{array}$ & $50.07 \%$ & A & B \\
\hline 3 & $\begin{array}{l}\text { You receive } \$ 100 \text { in } 1 \text { day if the } \\
\text { \# rolled is between } \underline{0} \underline{0} \underline{0} \underline{1} \text { and } \underline{5} \underline{\mathrm{o}} \underline{\mathrm{o}} \underline{\mathrm{o}} \text {. }\end{array}$ & $50.00 \%$ & $\begin{array}{l}\text { You receive } \$ 100 \text { in } 50 \text { days if the } \\
\text { \# rolled is between } \underline{0} \underline{0} \underline{0} \underline{1} \text { and } \underline{5} \underline{0} \underline{1} \underline{3} .\end{array}$ & $50.13 \%$ & A & B \\
\hline 4 & $\begin{array}{l}\text { You receive } \$ 100 \text { in } 1 \text { day if the } \\
\text { \# rolled is between } \underline{0} \underline{0} \underline{0} \underline{1} \text { and } \underline{5} \underline{0} \underline{o} \underline{0} \underline{0} \text {. }\end{array}$ & $50.00 \%$ & $\begin{array}{l}\text { You receive } \$ 100 \text { in } 50 \text { days if the } \\
\text { \# rolled is between } \underline{0} \underline{0} \underline{0} \underline{1} \text { and } \underline{\underline{0}} \underline{2} \underline{\mathrm{Z}} .\end{array}$ & $50.27 \%$ & A & B \\
\hline 5 & $\begin{array}{l}\text { You receive } \$ 100 \text { in } 1 \text { day if the } \\
\text { \# rolled is between } \underline{0} \underline{0} \underline{0} \underline{1} \text { and } 5 \underline{0} \underline{0} \underline{0} \text {. }\end{array}$ & $50.00 \%$ & $\begin{array}{l}\text { You receive } \$ 100 \text { in } 50 \text { days if the } \\
\text { \# rolled is between } \underline{0} \underline{0} \underline{0} \underline{1} \text { and } 5 \underline{0} \underline{\underline{0}} .\end{array}$ & $50.40 \%$ & A & B \\
\hline 6 & $\begin{array}{l}\text { You receive } \$ 100 \text { in } 1 \text { day if the } \\
\text { \# rolled is between } \underline{0} \underline{0} \underline{0} \underline{1} \text { and } \underline{5} \underline{0} \underline{0} \underline{0} .\end{array}$ & $50.00 \%$ & $\begin{array}{l}\text { You receive } \$ 100 \text { in } 50 \text { days if the } \\
\text { \# rolled is between } \underline{0} \underline{0} \underline{0} \underline{1} \text { and } 5 \underline{0} 5 \underline{4} .\end{array}$ & $50.54 \%$ & A & B \\
\hline 7 & $\begin{array}{l}\text { You receive } \$ 100 \text { in } 1 \text { day if the } \\
\text { \# rolled is between } \underline{0} \underline{0} \underline{0} \underline{1} \text { and } \underline{5} \underline{0} \underline{0} \underline{0} \text {. }\end{array}$ & $50.00 \%$ & $\begin{array}{l}\text { You receive } \$ 100 \text { in } 50 \text { days if the } \\
\text { \# rolled is between } \underline{0} \underline{0} \underline{0} \underline{1} \text { and } 5 \underline{0} \underline{6} \underline{8} .\end{array}$ & $50.68 \%$ & A & B \\
\hline 8 & $\begin{array}{l}\text { You receive } \$ 100 \text { in } \underline{1} \text { day if the } \\
\text { \# rolled is between } \underline{0} \underline{0} \underline{0} \underline{1} \text { and } \underline{5} \underline{0} \underline{o} \underline{0} .\end{array}$ & $50.00 \%$ & $\begin{array}{l}\text { You receive } \$ 100 \text { in } 50 \text { days if the } \\
\text { \# rolled is between } \underline{0} \underline{0} \underline{0} \underline{1} \text { and } 5 \underline{0} \underline{8} \underline{1} .\end{array}$ & $50.81 \%$ & A & B \\
\hline 9 & $\begin{array}{l}\text { You receive } \$ 100 \text { in } 1 \text { day if the } \\
\text { \# rolled is between } \underline{0} \underline{0} \underline{0} \underline{1} \text { and } \underline{5} \underline{\mathrm{o}} \underline{\mathrm{o}} \underline{\mathrm{o}} \text {. }\end{array}$ & $50.00 \%$ & $\begin{array}{l}\text { You receive } \$ 100 \text { in } 50 \text { days if the } \\
\text { \# rolled is between } \underline{0} \underline{0} \underline{0} \underline{1} \text { and } \underline{1} \underline{1} \underline{0} 9 .\end{array}$ & $51.09 \%$ & A & B \\
\hline 10 & $\begin{array}{l}\text { You receive } \$ 100 \text { in } 1 \text { day if the } \\
\text { \# rolled is between } \underline{0} \underline{0} \underline{0} \underline{1} \text { and } \underline{\underline{0}} \underline{\mathrm{o}} \underline{\mathrm{o}} \underline{\text {. }}\end{array}$ & $50.00 \%$ & $\begin{array}{l}\text { You receive } \$ 100 \text { in } 50 \text { days if the } \\
\text { \# rolled is between } \underline{0} \underline{0} \underline{0} \underline{1} \text { and } 5 \underline{1} \underline{\underline{6}} \underline{6} .\end{array}$ & $51.36 \%$ & A & B \\
\hline 11 & $\begin{array}{l}\text { You receive } \$ 100 \text { in } \underline{1} \text { day if the } \\
\text { \# rolled is between } \underline{0} \underline{0} \underline{0} \underline{1} \text { and } \underline{5} \underline{0} \underline{0} \underline{0} \text {. }\end{array}$ & $50.00 \%$ & $\begin{array}{l}\text { You receive } \$ 100 \text { in } 50 \text { days if the } \\
\text { \# rolled is between } \underline{0} \underline{0} \underline{0} \underline{1} \text { and } 5 \underline{1} \mathbf{Z} \underline{1} .\end{array}$ & $51.71 \%$ & A & B \\
\hline 12 & $\begin{array}{l}\text { You receive } \$ 100 \text { in } 1 \text { day if the } \\
\text { \# rolled is between } \underline{0} \underline{0} \underline{0} \underline{1} \text { and } \underline{5} \underline{o} \underline{0} \underline{0} .\end{array}$ & $50.00 \%$ & $\begin{array}{l}\text { You receive } \$ 100 \text { in } 50 \text { days if the } \\
\text { \# rolled is between } \underline{0} \underline{0} \underline{0} \underline{1} \text { and } \underline{\underline{2}} \underline{\mathbf{0}} \underline{5} .\end{array}$ & $52.05 \%$ & A & B \\
\hline 13 & $\begin{array}{l}\text { You receive } \$ 100 \text { in } 1 \text { day if the } \\
\text { \# rolled is between } \underline{0} \underline{0} \underline{0} \underline{1} \text { and } \underline{5} \underline{0} \underline{0} \underline{0} .\end{array}$ & $50.00 \%$ & $\begin{array}{l}\text { You receive } \$ 100 \text { in } 50 \text { days if the } \\
\text { \# rolled is between } \underline{0} \underline{0} \underline{0} \underline{1} \text { and } 5 \underline{2} \underline{7} \underline{6} \text {. }\end{array}$ & $52.76 \%$ & A & B \\
\hline 14 & $\begin{array}{l}\text { You receive } \$ 100 \text { in } 1 \text { day if the } \\
\text { \# rolled is between } \underline{0} \underline{0} \underline{0} \underline{1} \text { and } \underline{5} \underline{0} \underline{0} \underline{0} \text {. }\end{array}$ & $50.00 \%$ & $\begin{array}{l}\text { You receive } \$ 100 \text { in } 50 \text { days if the } \\
\text { \# rolled is between } \underline{0} \underline{0} \underline{0} \underline{1} \text { and } 5 \underline{5} \underline{2} .\end{array}$ & $55.29 \%$ & A & B \\
\hline
\end{tabular}

Task Number

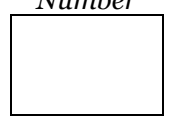

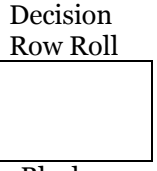

Black-20

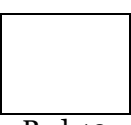

Red-10
Outcome Roll

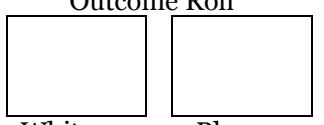

White-10
Blue-10

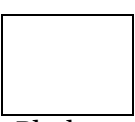

Black-10 


\section{Experiment 2 Task D Decision Sheet (Short Horizon)}

\section{Decision Table}

\begin{tabular}{|c|c|c|c|c|c|c|}
\hline \multirow[t]{2}{*}{ Decision } & \multicolumn{2}{|l|}{$\begin{array}{c}\text { Option } A \\
\text { (Pays } \$ 100 \text { in } 14 \text { days) }\end{array}$} & \multicolumn{2}{|l|}{$\begin{array}{c}\text { Option B } \\
\text { (Pays } \$ 100 \text { in } 21 \text { days) }\end{array}$} & \multicolumn{2}{|c|}{$\begin{array}{c}\text { Preferred } \\
\text { Option } \\
\text { (Circle } \\
\text { A or B) } \\
\end{array}$} \\
\hline & Winning Numbers for Option A & $\begin{array}{l}\text { Chances of } \\
\text { winning }\end{array}$ & Winning Numbers for Option B & $\begin{array}{l}\text { Chances of } \\
\text { winning }\end{array}$ & & \\
\hline 1 & $\begin{array}{l}\text { You receive } \$ 100 \text { in } 14 \text { days if the } \\
\text { \# rolled is between } \underline{0} \underline{0} \underline{0} \underline{1} \text { and } \underline{\underline{0}} \underline{\mathrm{O}} \underline{0} \underline{0} \text {. }\end{array}$ & $50.00 \%$ & $\begin{array}{l}\text { You receive } \$ 100 \text { in } 21 \text { days if the \# } \\
\text { rolled is between } \underline{0} \underline{0} \underline{0} \underline{1} \text { and } \underline{\underline{0}} \underline{0} \underline{0} \underline{0} \text {. }\end{array}$ & $50.00 \%$ & A & B \\
\hline 2 & $\begin{array}{l}\text { You receive } \$ 100 \text { in } 14 \text { days if the } \\
\text { \# rolled is between } \underline{0} \underline{0} \underline{0} \underline{1} \text { and } 5 \underline{0} \underline{0} \underline{0} .\end{array}$ & $50.00 \%$ & $\begin{array}{l}\text { You receive } \$ 100 \text { in } 21 \text { days if the } \\
\text { \# rolled is between } \underline{0} \underline{0} \underline{0} \underline{1} \text { and } 5 \underline{0} \underline{0} \underline{1} .\end{array}$ & $50.01 \%$ & A & B \\
\hline 3 & $\begin{array}{l}\text { You receive } \$ 100 \text { in } 14 \text { days if the } \\
\text { \# rolled is between } \underline{0} \underline{0} \underline{0} \underline{1} \text { and } \underline{5} \underline{0} \underline{0} \underline{0} .\end{array}$ & $50.00 \%$ & $\begin{array}{l}\text { You receive } \$ 100 \text { in } 21 \text { days if the } \\
\text { \# rolled is between } \underline{0} \underline{0} \underline{0} \underline{1} \text { and } \underline{5} \underline{0} \underline{0} \underline{2} .\end{array}$ & $50.02 \%$ & A & B \\
\hline 4 & $\begin{array}{l}\text { You receive } \$ 100 \text { in } 14 \text { days if the } \\
\text { \# rolled is between } \underline{0} \underline{0} \underline{0} \underline{1} \text { and } \underline{5} \underline{0} \underline{0} \underline{0} .\end{array}$ & $50.00 \%$ & $\begin{array}{l}\text { You receive } \$ 100 \text { in } 21 \text { days if the } \\
\text { \# rolled is between } \underline{0} \underline{0} \underline{0} \underline{1} \text { and } \underline{5} \underline{0} \underline{0} 4 .\end{array}$ & $50.04 \%$ & A & B \\
\hline 5 & $\begin{array}{l}\text { You receive } \$ 100 \text { in } 14 \text { days if the } \\
\text { \# rolled is between } \underline{0} \underline{0} \underline{0} \underline{1} \text { and } 5 \underline{0} \underline{0} \underline{0} .\end{array}$ & $50.00 \%$ & $\begin{array}{l}\text { You receive } \$ 100 \text { in } 21 \text { days if the } \\
\text { \# rolled is between } \underline{0} \underline{0} \underline{0} \underline{1} \text { and } 5 \underline{0} \underline{0} \underline{6} .\end{array}$ & $50.06 \%$ & A & B \\
\hline 6 & $\begin{array}{l}\text { You receive } \$ 100 \text { in } 14 \text { days if the } \\
\text { \# rolled is between } \underline{0} \underline{0} \underline{0} \underline{1} \text { and } \underline{5} \underline{0} \underline{0} \underline{0} .\end{array}$ & $50.00 \%$ & $\begin{array}{l}\text { You receive } \$ 100 \text { in } 21 \text { days if the } \\
\text { \# rolled is between } \underline{0} \underline{0} \underline{0} \underline{1} \text { and } \underline{\underline{0}} \underline{0} \underline{0} \underline{8} .\end{array}$ & $50.08 \%$ & A & B \\
\hline 7 & $\begin{array}{l}\text { You receive } \$ 100 \text { in } 14 \text { days if the } \\
\text { \# rolled is between } \underline{0} \underline{0} \underline{0} \underline{1} \text { and } 5 \underline{0} \underline{0} \underline{0} .\end{array}$ & $50.00 \%$ & $\begin{array}{l}\text { You receive } \$ 100 \text { in } 21 \text { days if the } \\
\text { \# rolled is between } \underline{0} \underline{0} \underline{0} \underline{1} \text { and } 5 \underline{0} \underline{1} \underline{0} \text {. }\end{array}$ & $50.10 \%$ & A & B \\
\hline 8 & $\begin{array}{l}\text { You receive } \$ 100 \text { in } 14 \text { days if the } \\
\text { \# rolled is between } \underline{0} \underline{0} \underline{0} \underline{1} \text { and } 5 \underline{0} \underline{0} \underline{0} \text {. }\end{array}$ & $50.00 \%$ & $\begin{array}{l}\text { You receive } \$ 100 \text { in } 21 \text { days if the } \\
\text { \# rolled is between } \underline{0} \underline{0} \underline{0} \underline{1} \text { and } 5 \underline{0} \underline{1} \underline{2} .\end{array}$ & $50.12 \%$ & A & B \\
\hline 9 & $\begin{array}{l}\text { You receive } \$ 100 \text { in } 14 \text { days if the } \\
\text { \# rolled is between } \underline{0} \underline{0} \underline{0} \underline{1} \text { and } \underline{5} \underline{0} \underline{0} \underline{0} .\end{array}$ & $50.00 \%$ & $\begin{array}{l}\text { You receive } \$ 100 \text { in } 21 \text { days if the } \\
\text { \# rolled is between } \underline{0} \underline{0} \underline{0} \underline{1} \text { and } \underline{5} \underline{0} \underline{1} \underline{5} .\end{array}$ & $50.15 \%$ & A & B \\
\hline 10 & $\begin{array}{l}\text { You receive } \$ 100 \text { in } 14 \text { days if the } \\
\text { \# rolled is between } \underline{0} \underline{0} \underline{0} \underline{1} \text { and } \underline{5} \underline{0} \underline{0} \underline{0} .\end{array}$ & $50.00 \%$ & $\begin{array}{l}\text { You receive } \$ 100 \text { in } 21 \text { days if the } \\
\text { \# rolled is between } \underline{0} \underline{0} \underline{0} \underline{1} \text { and } 5 \underline{0} \underline{1} \underline{q} .\end{array}$ & $50.19 \%$ & A & B \\
\hline 11 & $\begin{array}{l}\text { You receive } \$ 100 \text { in } 14 \text { days if the } \\
\text { \# rolled is between } \underline{0} \underline{0} \underline{0} \underline{1} \text { and } 5 \underline{0} \underline{0} \underline{0} \underline{0} .\end{array}$ & $50.00 \%$ & $\begin{array}{l}\text { You receive } \$ 100 \text { in } 21 \text { days if the } \\
\text { \# rolled is between } \underline{0} \underline{0} \underline{0} \underline{1} \text { and } 5 \underline{0} \underline{2} \underline{4} .\end{array}$ & $50.24 \%$ & A & B \\
\hline 12 & $\begin{array}{l}\text { You receive } \$ 100 \text { in } 14 \text { days if the } \\
\text { \# rolled is between } \underline{0} \underline{0} \underline{0} \underline{1} \text { and } \underline{5} \underline{0} \underline{0} \underline{0} .\end{array}$ & $50.00 \%$ & $\begin{array}{l}\text { You receive } \$ 100 \text { in } 21 \text { days if the } \\
\text { \# rolled is between } \underline{0} \underline{0} \underline{0} \underline{1} \text { and } \underline{5} \underline{0} \underline{2} 9 .\end{array}$ & $50.29 \%$ & A & B \\
\hline 13 & $\begin{array}{l}\text { You receive } \$ 100 \text { in } 14 \text { days if the } \\
\text { \# rolled is between } \underline{0} \underline{0} \underline{0} \underline{1} \text { and } 5 \underline{0} \underline{0} \underline{0} .\end{array}$ & $50.00 \%$ & $\begin{array}{l}\text { You receive } \$ 100 \text { in } 21 \text { days if the } \\
\text { \# rolled is between } \underline{0} \underline{0} \underline{0} \underline{1} \text { and } 5 \underline{0} 3 \underline{8} \text {. }\end{array}$ & $50.38 \%$ & A & B \\
\hline 14 & $\begin{array}{l}\text { You receive } \$ 100 \text { in } 14 \text { days if the } \\
\text { \# rolled is between } \underline{0} \underline{0} \underline{0} \underline{1} \text { and } 5 \underline{0} \underline{0} \underline{0} .\end{array}$ & $50.00 \%$ & $\begin{array}{l}\text { You receive } \$ 100 \text { in } 21 \text { days if the } \\
\text { \# rolled is between } \underline{0} \underline{0} \underline{0} 1 \text { and } 5 \underline{0} Z \underline{2} .\end{array}$ & $50.72 \%$ & A & B \\
\hline
\end{tabular}

Task Number

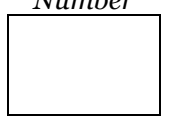

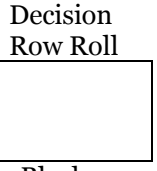

Black-20

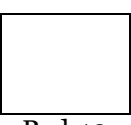

Red-10
Outcome Roll

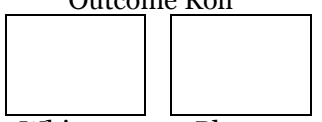

White-10
Blue-10

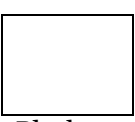

Black-10 